\title{
Thyrocyte-specific inactivation of p53 and Pten results in anaplastic thyroid carcinomas faithfully recapitulating human tumors
}

\author{
Valeria G. Antico Arciuch ${ }^{1 *}$, Marika A. Russo ${ }^{1 *}$, Mariavittoria Dima $^{1}$, Kristy S. \\ Kang ${ }^{1}$, Florence Dasrath ${ }^{1}$, Xiao-Hui Liao ${ }^{3}$, Samuel Refetoff ${ }^{3,4}$, Cristina Montagna ${ }^{2}$, \\ and Antonio Di Cristofano ${ }^{1}$ \\ ${ }^{1}$ Department of Developmental and Molecular Biology, Albert Einstein College of Medicine, Bronx, NY \\ 2 Department of Genetics, Albert Einstein College of Medicine, Bronx, NY \\ 3 Department of Medicine, University of Chicago, Chicago, IL \\ ${ }^{4}$ Department of Pediatrics and Committee on Genetics, University of Chicago, Chicago, IL \\ *Denotes equal contribution
}

Correspondence to: A. Di Cristofano, email: antonio.dicristofano@einstein.yu.edu

Keywords: thyroid cancer, mouse model, anaplastic, glycolysis, PI3K, Pten, p53

Received: December 8, 2011, Accepted: December 9, 2011, Published: December 20, 2011

Copyright: $\odot$ Arciuch et al. This is an open-access article distributed under the terms of the Creative Commons Attribution License, which permits unrestricted use, distribution, and reproduction in any medium, provided the original author and source are credited.

ABSTRACT:

Anaplastic thyroid carcinoma (ATC) is the most aggressive form of thyroid cancer, and often derives from pre-existing well-differentiated tumors. Despite a relatively low prevalence, it accounts for a disproportionate number of thyroid cancer-related deaths, due to its resistance to any therapeutic approach. Here we describe the first mouse model of ATC, obtained by combining in the mouse thyroid follicular cells two molecular hallmarks of human ATC: activation of PI3K (via Pten deletion) and inactivation of p53. By 9 months of age, over $75 \%$ of the compound mutant mice develop aggressive, undifferentiated thyroid tumors that evolve from pre-existing follicular hyperplasia and carcinoma. These tumors display all the features of their human counterpart, including pleomorphism, epithelial-mesenchymal transition, aneuploidy, local invasion, and distant metastases. Expression profiling of the murine ATCs reveals a significant overlap with genes found deregulated in human ATC, including genes involved in mitosis control. Furthermore, similar to the human tumors, [Pten, $p 53]^{\text {thyr-/- }}$ tumors and cells are highly glycolytic and remarkably sensitive to glycolysis inhibitors, which synergize with standard chemotherapy. Taken together, our results show that combined PI3K activation and p53 loss faithfully reproduce the development of thyroid anaplastic carcinomas, and provide a compelling rationale for targeting glycolysis to increase chemotherapy response in ATC patients.

\section{INTRODUCTION}

Thyroid cancer is the most common endocrine neoplasm, and one of the few tumor types for which incidence has been increasing over the past 20 years [1]. Well-differentiated thyroid cancers (papillary and follicular) have generally a good prognosis and can be effectively managed through a combination of surgery and radioactive iodine treatment [2]. Anaplastic thyroid carcinoma (ATC) represents the most aggressive and undifferentiated subtype of thyroid cancer. It often coexists with well-differentiated tumors, suggesting that it arises from pre-existing follicular or papillary tumors $[3,4]$. Although it comprises less than $5 \%$ of thyroid malignancies, ATC accounts for up to $40 \%$ of deaths from thyroid cancer [5]. In fact, ATC is almost invariably lethal, with no effective therapy available $[6,7]$. Thus, its median survival of around 4 months, due to rapid onset, tracheal and esophageal invasion, and uncontrolled metastases to the lungs and, to a less extent, to bones, skin and brain, has not changed in more than half a century [8]. Dedifferentiation, a hallmark of ATC, is manifested 
by loss of specific thyroid cell characteristics and functions, including expression of thyroglobulin, thyroid peroxidase, thyroid stimulating hormone receptor and the $\mathrm{Na} / \mathrm{I}$ symporter, NIS [9]. Other ATC characteristics include pleomorphism, with often coexisting areas of squamoid, spindle cell, and giant cell morphology [10], epithelial-to-mesenchymal transition [7], and neutrophilic infiltrate [11].

Molecular characterization of ATCs has revealed a high degree of chromosomal instability and aneuploidy [12]. In addition, common alterations in a number of signal transduction pathways have been identified. Molecular changes that characterize ATC have been recently reviewed in a number of publications $[9,13$, 14], and involve most often p53 loss or inactivation, and activation of the PI3K cascade, of RAS family members, or of BRAF.

One major obstacle to the development of more effective therapeutic approaches to ATC has been the lack of an immunocompetent, autochthonous mouse model closely recapitulating the clinicopathological features of human ATC. In spite of significant advancements, most genetically engineered mouse models described to date only develop differentiated thyroid cancer, such as PTC [15-17] and FTC [18-20]. One notable exception is represented by the $B r a f^{\mathrm{V} 600 \mathrm{E}}$ transgenic model, which develops poorly differentiated foci from concurrent papillary lesions [21]

In this study, we report the characterization of the first mouse model of ATC, based on the simultaneous activation of the PI3K signaling cascade and inactivation of $p 53$ in the mouse thyroid epithelial cells. The tumors developing in these mice closely phenocopy human ATCs,
A

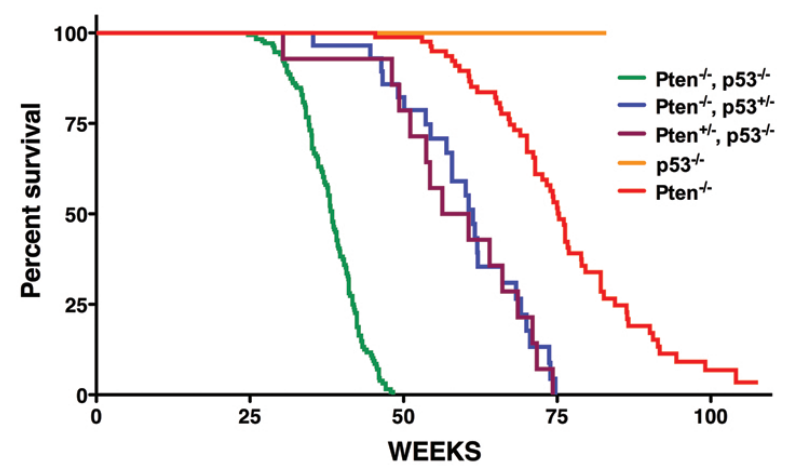

$\mathrm{D}$

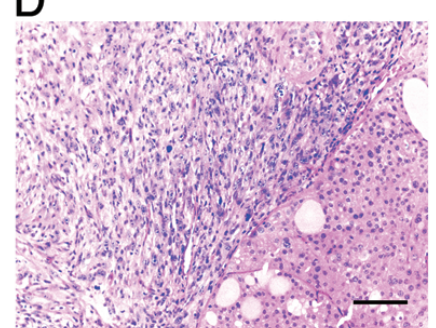

$\mathrm{H}$

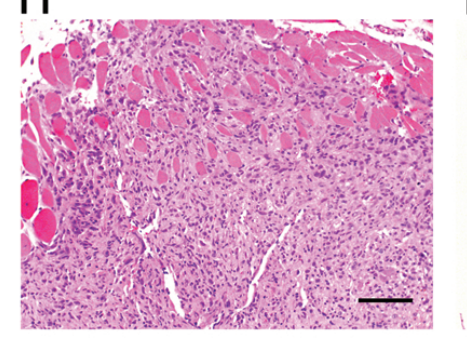

$\mathrm{E}$

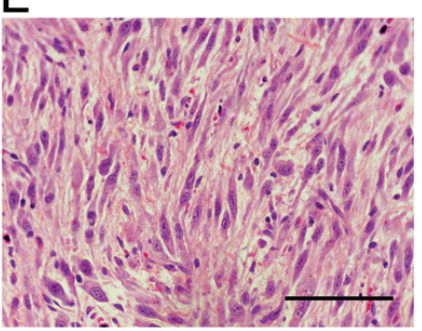

\section{I}

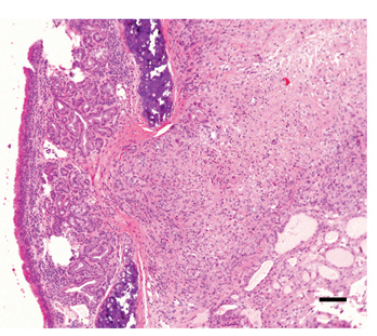

B

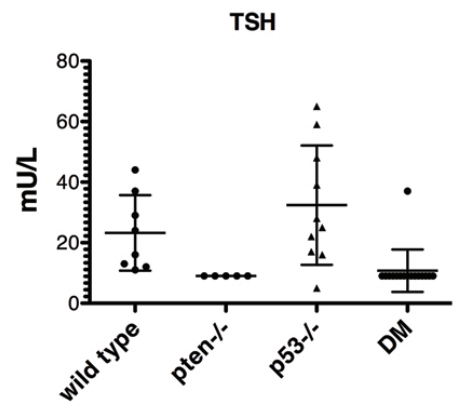

$\mathrm{F}$
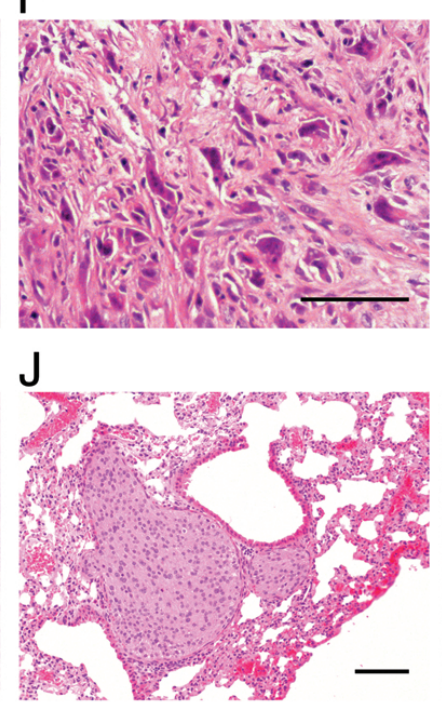

C

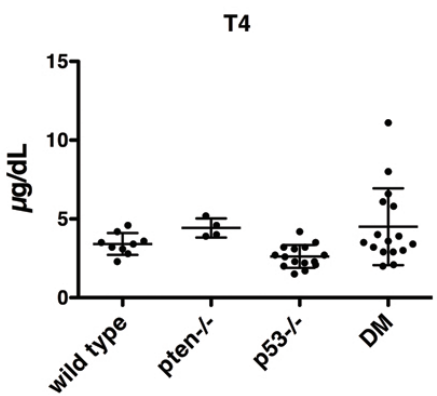

G

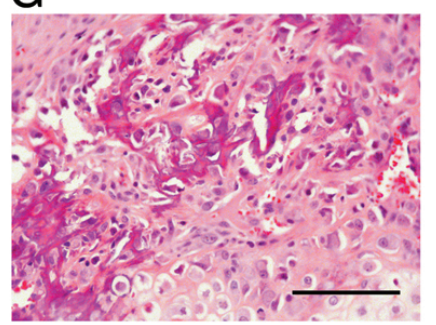

$\mathrm{K}$

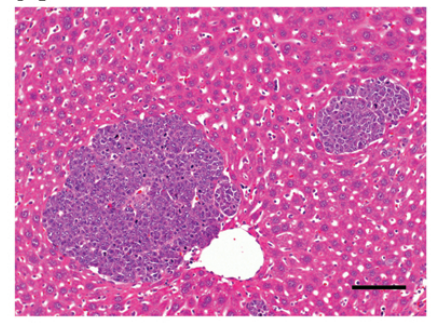

Figure 1: Clinicopathological features of $[\text { Pten, } p 53]^{\text {thyr-/- }}$ mice. (A) Kaplan-Meyer analysis of the effect of progressive $p 53$ deletion on the survival of Pten ${ }^{\text {thyr-/ }}$ mice. $(\mathrm{B}, \mathrm{C}) \mathrm{TSH}$ and T4 serum levels in control, single mutant and double mutant (DM) mice. (D-K) Histopatological features of tumors developing in [Pten, p53 $]^{\text {thyr-/ }}$ mice. (D) Anaplastic carcinoma (left) flanking an area of welldifferentiated follicular carcinoma (right). Undifferentiated tumors display areas of spindle cell morphology (E), with frequent giant cells $(\mathrm{F})$, and occasional bone metaplasia $(\mathrm{G})$. Tumors invade locally into the muscle $(\mathrm{H})$, and the trachea $(\mathrm{I})$, and metastasize to the lungs $(\mathrm{J})$ or, sporadically, to the liver $(\mathrm{K})$. Bar: $100 \mu \mathrm{m}$. 
undergo the glycolytic shift known as Warburg effect, and are highly sensitive to the therapeutic use of glycolytic inhibitors. Thus, this model represents a novel, powerful tool to understand the biology of human thyroid anaplastic carcinomas, and to develop innovative therapeutic approaches for what is today still a lethal disease.
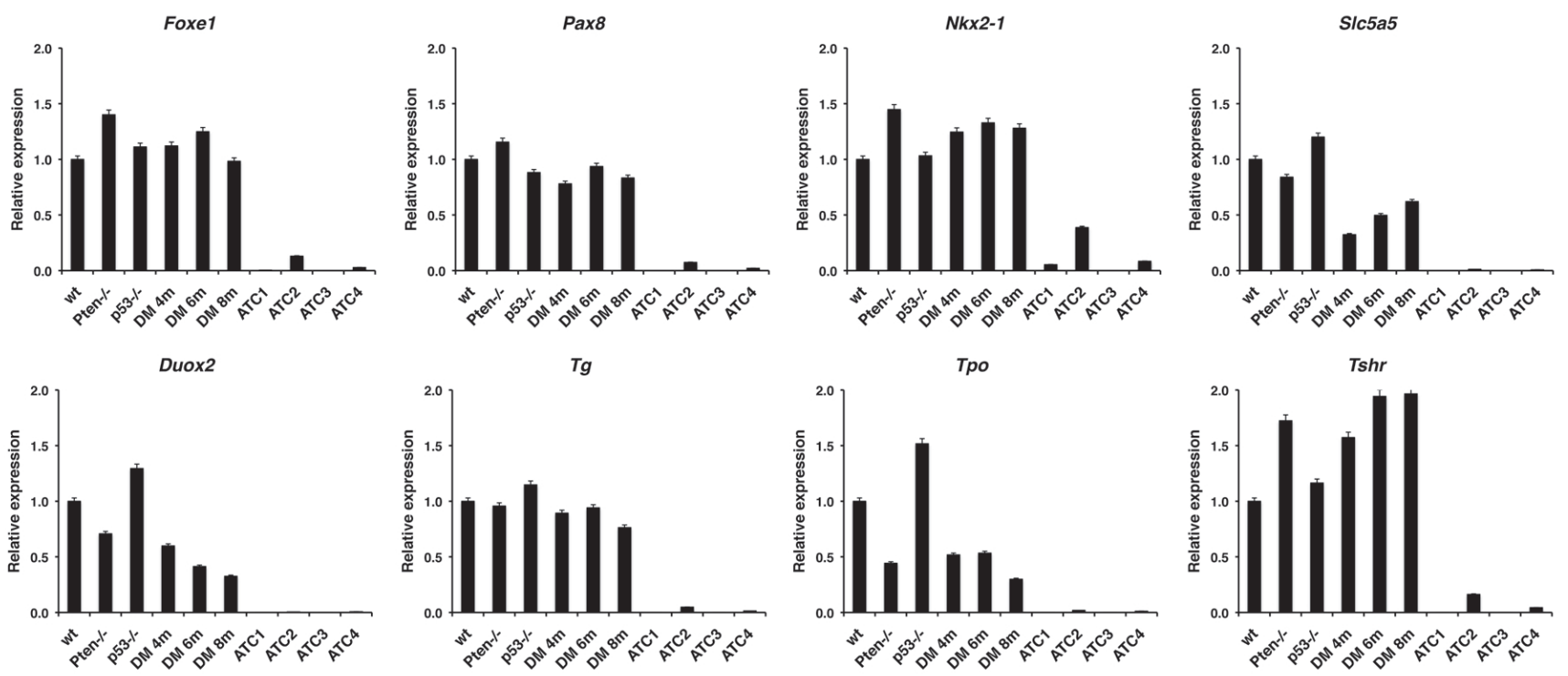

Figure 2. Expression profiling by real-time PCR of a panel of thyroid differentiation markers using thyroid pools from 4-month old control and single mutant mice, ATC-free, progressively older (4, 6, 8 months) double mutants, and histologically confirmed ATCs from 8- to 9-month old double mutants. 


\section{RESULTS}

\section{Anaplastic thyroid carcinoma development in $[\text { Pten, p53 }]^{\text {thyr-/- }}$ mice}

Mice with a targeted deletion of the Pten tumor suppressor gene in the thyroid follicular cells exhibit constitutive PI3K pathway activation and develop, from birth, hyperplastic glands that progress to nodular lesions by $6-10$ months of age [22] and to well-differentiated follicular carcinomas after one year of age [19]. Building on available clinicopathological data that point at $p 53$ as the most commonly mutated or deleted gene in anaplastic thyroid tumors, we crossed the Pten mutants with mice carrying a floxed $p 53$ allele in order to model more aggressive thyroid tumors. Thyroid-specific $p 53$ loss did not cause any overt phenotype (Figure 1A and data not shown). Conversely, concomitant loss of p53 dramatically reduced the survival of Pten ${ }^{\text {thyr-l}}$ - mice (median survival 38.4 weeks vs. 75.3 weeks), while reduction to heterozygosity of either allele, in the absence of the other, resulted in an intermediate phenotype (median survival: 61.3 weeks for $\left[\right.$ Pten $\left.^{\text {thyr-// }}, p 53^{\text {thyr }+/}\right]$ mice, and 58.45 weeks for $\left[\right.$ Pten $^{\text {thyr }+/ \text {, }}$ $\left.p 53^{\text {thyr }-/}\right]$ mice) (Figure 1A). Similar to $P$ ten $^{\text {thyr }-/}$ mice, $[\text { Pten, } p 53]^{\text {thyr }-}$ compound mutants displayed drastically reduced Thyroid-Stimulating Hormone (TSH) serum
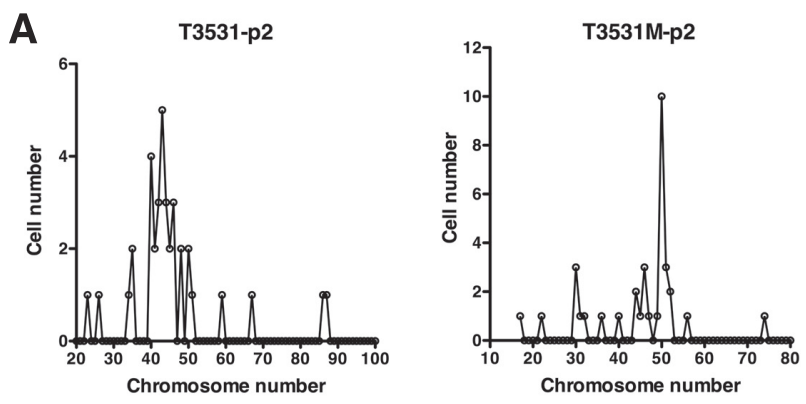

B
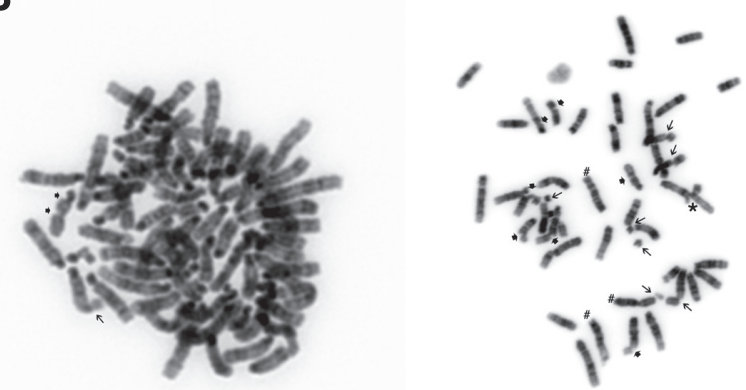

Figure 3: Mouse ATCs display chromosomal instability and aneuploidy. (A) Chromosome counts in two representative early passage (p2) primary cultures from histologically confirmed ATCs. Note the wide distribution of chromosome numbers within the same culture. (B) Karyotypic analysis of two representative cells from independent tumors, showing chromatid breaks (thick arrows), chromosome breaks (thin arrows), translocations (\#), and complex rearrangements $(*)$.

levels. However, the absence of significantly increased T4 hormone levels suggests that TSH suppression is not the consequence of relieving the physiological negative feedback normally induced by elevated thyroid hormone levels (Figure 1B, C).

Post mortem analysis of 8-10 month old [Pten, p53] thyr- - mutants revealed in all cases a strikingly enlarged thyroid gland (average gland weight $392 \pm 350 \mathrm{mg}$, vs. $3.7 \pm 1.1 \mathrm{mg}$ in age-matched controls) causing severe tracheal compression and adhering to adjacent tissues. Histopathological analysis showed the coexistence of small remnants of well-differentiated follicular carcinomas, similar to those developing in aging Pten $^{\text {thyr- }- \text { - }}$ mice, and of more extensive pleomorphic areas (Figure 1D) exhibiting, as in human anaplastic carcinomas, spindle cell morphology (Figure 1E), giant, osteoclastlike, multinucleated cells (Figure 1F), and even areas of osseous metaplasia (Figure 1G). These aggressive tumors invaded locally into the muscle (Figure $1 \mathrm{H}$ ) and trachea (Figure 1I) and, in 28\% of mice, metastasized to the lungs (Figure 1J) or, albeit less often, to the liver (Figure $1 \mathrm{~K}$ ). Conversely, analysis of thyroids from 4-8 month old [Pten, $p 53]^{\text {thyr-/ }}$ mice only showed areas of well differentiated follicular carcinomas, indistinguishable from those developing in older Pten $^{\text {thyr- } /}$ mice (data not shown). Thus, combined loss of $p 53$ and PI3K activation in the thyroid follicular cells results in the development of aggressive, metastatic tumors closely resembling human thyroid anaplastic carcinomas.

A

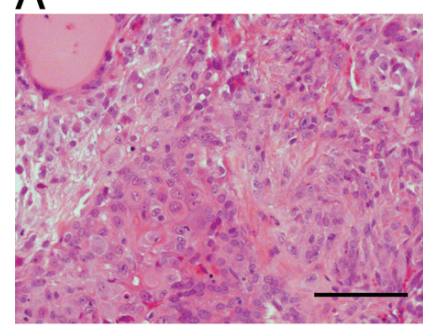

C

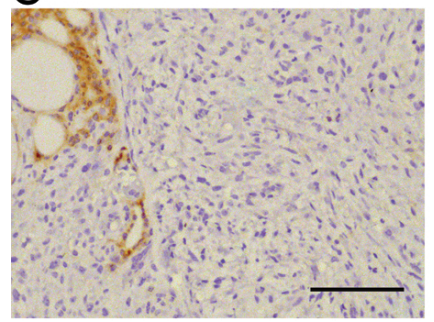

Figure 4: $[\text { Pten, p53 }]^{\text {thyr-/- }}$ ATCs undergo EMT. (A) H\&E staining of a representative tumor area containing both a follicular carcinoma (left) and an anaplastic carcinoma (right) component. (B-D) Immunohistochemical detection of phospho-Smad 2 (B), E-cadherin (C), and vimentin (D). Bar: $100 \mu \mathrm{m}$. 


\section{Mouse ATCs undergo dedifferentiation, genomic instability, and EMT}

Loss of thyrocyte differentiation is a hallmark of human ATC. We used real time PCR to measure the expression levels of a panel of genes associated with thyroid differentiation and function in freshly dissected glands and tumors. Expression of the Foxe1, Pax8, and Nkx2-1 transcription factors, as well as of the thyroidspecific genes Duox2, Tpo, Tg, Tshr, and Slc5a 5 (Nis) was generally not altered in single mutants nor in [Pten, p53] thyr-/ mice up to 8 months of age, before the development of frank ATC. However, expression of each of these markers was reduced to almost undetectable levels in every anaplastic tumor analyzed (Figure 2), supporting
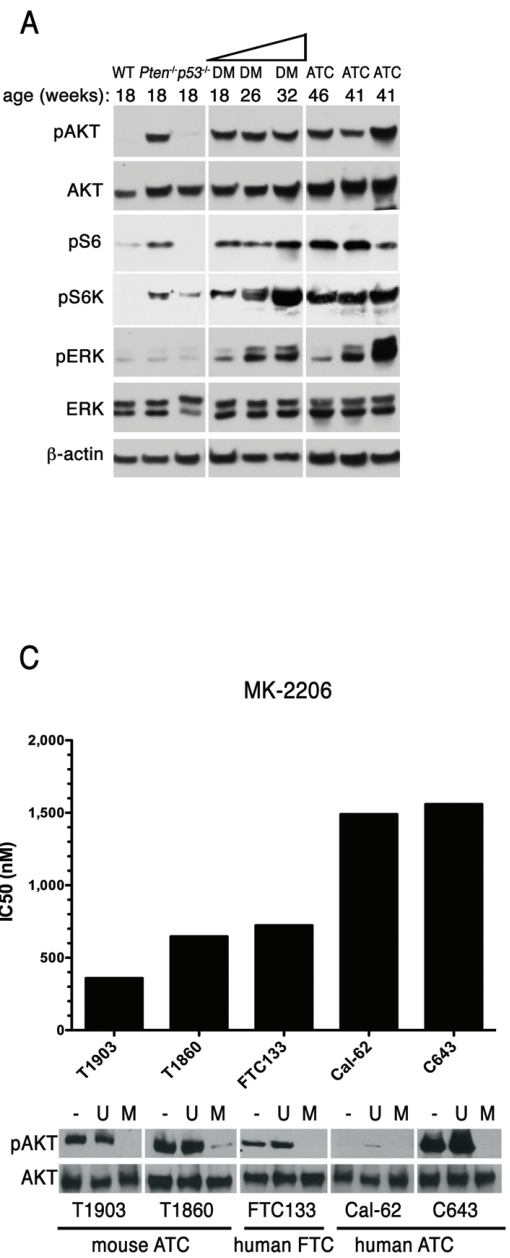

the notion that the tumors developing in the compound mutants are indeed undifferentiated carcinomas.

A second frequent aspect of human ATC is an elevated degree of genomic instability, leading to marked aneuploidy. We analyzed metaphase spreads from early passage primary cultures of several histologically confirmed anaplastic carcinomas, and found that these cells were invariably aneuploid (Figure 3A), with evidence of widespread chromosomal damage, including chromosome and chromatid breaks, complex rearrangements, translocations, premature centromere division, and the presence of chromosomal debris (Figure 3B). Thus, combined loss of the Pten and p53 tumor suppressors leads to tumors that display genomic instability.

To further validate the $[\text { Pten, } p 53]^{\text {thyr-/ }}$ strain as a model of human ATC, we performed immunohistochemistry on paraffin sections from 9-10 month old mice displaying

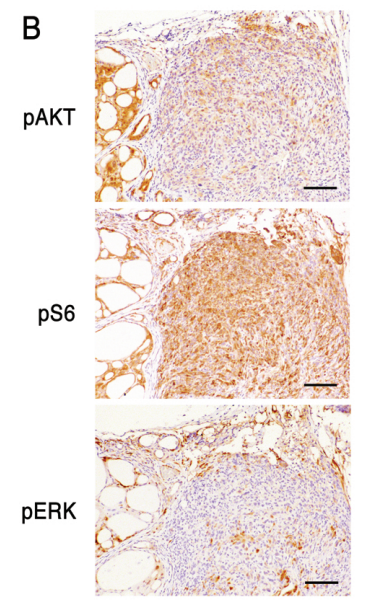

U0126

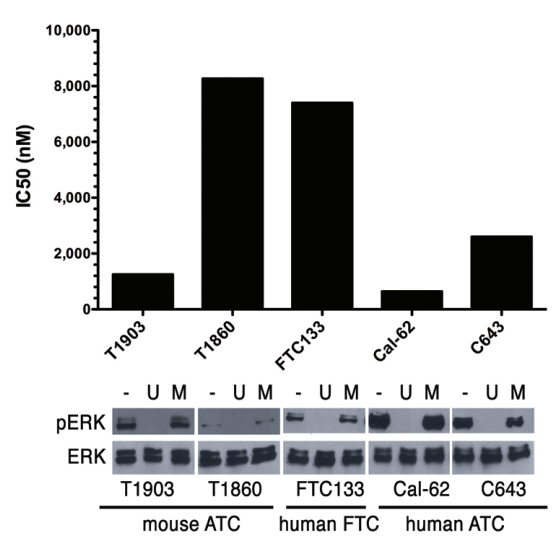

Figure 5: ATCs are addicted to driver gene signaling. (A) Western blotting analysis of the activation status of Akt and MAPK pathways in 4-month old control and single mutant mice, ATC-free, progressively older (4, 6, 8 months) double mutants, and histologically confirmed ATCs from 8- to 9-month old double mutants. (B) immunohistochemical detection of activated Akt, S6 ribosomal protein, and ERK1/2 in tumor areas with both well-differentiated and anaplastic components. (C) $\mathrm{IC}_{50}$ values for an Akt inhibitor (MK-2206) and a MEK inhibitor (U0126) in a panel of mouse and human anaplastic (ATC) and follicular (FTC) carcinoma cell lines. On the bottom, a Western blotting showing the effect on the activation of Akt and ERK1/2 of one hour exposure to these inhibitors (MK-2206: 500nM, U0126: $10 \mu \mathrm{M})$. 
both well-differentiated and undifferentiated tumor areas in order to determine whether these tumors display epithelial-to-mesenchymal transition (EMT). Strikingly, the undifferentiated area of all the tumors analyzed had lost the expression of the epithelial marker E-cadherin, had acquired the expression of the mesenchymal marker Vimentin, and displayed high levels of phosphorylated Smad2 (Figure 4). No EMT was detected on thyroid sections from younger mice (not shown). These data show that the tumors developing in the compound mutants invariably undergo EMT, and strongly suggest that this process is, at least in part, under the control of elevated Tgf- $\beta$ signaling.

A large subset of human ATCs is characterized by activating $B R A F$ or $R A S$ mutations. To determine whether the ATCs developing in [Pten, $p 53]^{\text {thyr-/ }}$ mice have somatic activating mutations in either Braf or in one of the three Ras genes, we sequenced the known hotspots (Braf exons
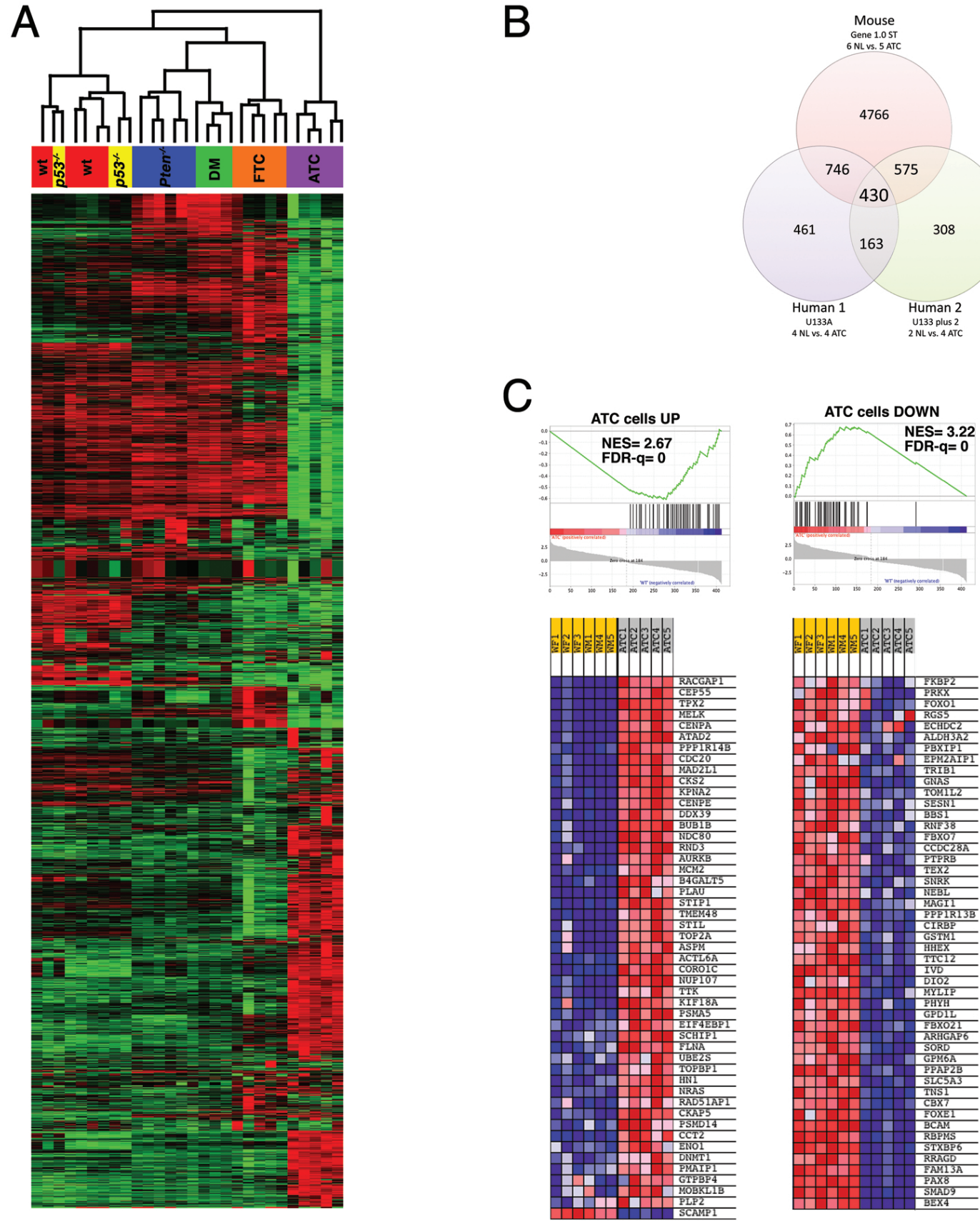
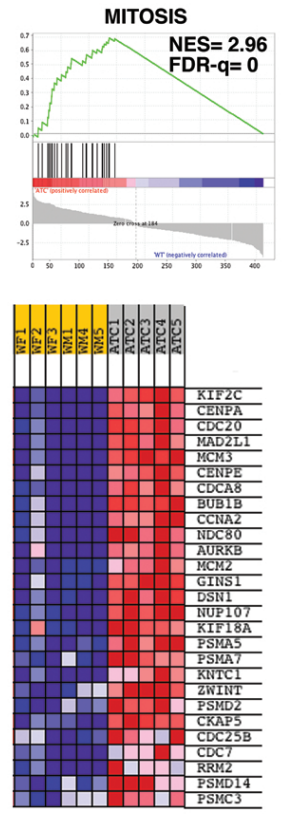

Figure 6: Expression profiling validates the $[P t e n, p 53]^{\text {thyr-/- }}$ mouse as a clinically relevant model of human ATC. (A) Hierarchical clustering showing the unique expression profile of mouse ATCs when compared to controls, single mutants, ATC-free double

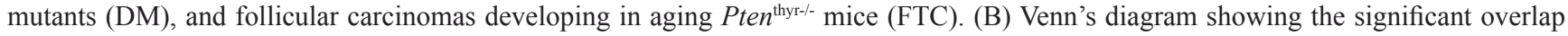
between genes differentially regulated in mouse and human ATCs. (C) GSEA analysis of the 430 genes common to mouse and human ATC, showing significant enrichment in genes previously shown to be altered in human ATC cell lines as well as genes involved in the control of mitosis. 
11 and 15, H-; N-, and Kras exons 1 and 2) in five cell lines established from tumors developed by [Pten, p53] thyr-/ double mutant mice. All cell lines had wild type sequences, strongly suggesting that neither Braf nor Ras isoforms are involved in ATC development in this mouse model (data not shown).

\section{ATCs are addicted to driver gene signaling}

Loss of Pten is anticipated to lead to constitutive phosphorylation of Akt and deregulation of its downstream targets. Indeed, western blot analysis of thyroid extracts from control, single, and young double mutants showed elevated $\mathrm{pSer}^{473}$-Akt, $\mathrm{pThr}{ }^{389}$-S6k, and $\mathrm{pSer}^{240 / 244}$-S6 in thyroids lacking Pten (Figure 5A). Double mutant glands also displayed moderate levels of pERK1/2. ATCs were characterized by a somewhat increased phosphorylation of S6, and by variable levels of pERK1/2. However, when phosphorylation and activation of these proteins was examined by IHC, we found that Akt phosphorylation was higher in the remnants of well-differentiated lesions within the tumor than in the anaplastic component, which instead showed higher levels of pS6 (Figure 5B). This finding suggests that the well-known negative feedback mediated by S6k and IRS-1 [23] might be favored or enhanced in ATCs. Furthermore, it may underline a reduced dependence of fully developed ATCs on Akt signaling.

In the same tumors, ERK1/2 activation was restricted to scattered patches of cells, often near the invasive edges of the undifferentiated components.

The accumulating genetic alterations consequent the high degree of genomic instability within ATCs might alter the dependence of these tumors on their driver oncogenic alteration, i.e. increased Akt signaling. We used two cell lines, T1860 and T1903, which we have derived from anaplastic tumors developed by $[\text { Pten, } p 53]^{\text {thyr }-/}$ mice, to determine the sensitivity of these murine ATCs cells to

Table 1: Top 25 deregulated pathways identified in mouse ATCs, using the Ingenuity Pathways Analysis (IPA) system.

\begin{tabular}{|l|l|l|c|}
\hline Ingenuity Canonical Pathways & P-value & Ratio & $\begin{array}{c}\text { Molecules } \\
\text { in pathway }\end{array}$ \\
\hline Hepatic Fibrosis / He patic Ste llate CeII Activation & 0.00000 & 0.347 & $51 / 147$ \\
\hline Leuk ocyte Extravas ation Signaling & 0.00000 & 0.276 & $55 / 199$ \\
\hline LPS/L-1 Mediated Inhibition of RXR Function & 0.00000 & 0.247 & $54 / 219$ \\
\hline Propanoate Metabolism & 0.00000 & 0.190 & $23 / 121$ \\
\hline Role of Osteoblasts, Osteoclasts and Chondrocytes in Rhe umatoid Arthritis & 0.00000 & 0.246 & $59 / 240$ \\
\hline LXR/RXR Activation & 0.00002 & 0.280 & $26 / 93$ \\
\hline Valine, Leucine and Isoleucine Degradation & 0.00002 & 0.226 & $24 / 106$ \\
\hline Metabolism of Xenobiotics by Cytochrome P450 & 0.00003 & 0.142 & $28 / 197$ \\
\hline Atherosclerosis Signaling & 0.00003 & 0.271 & $29 / 107$ \\
\hline Aryl Hydrocarbon Receptor Signaling & 0.00004 & 0.239 & $38 / 157$ \\
\hline Urea Cycle and Metabolism of Amino Groups & 0.00005 & 0.179 & $14 / 78$ \\
\hline Fatty Acid Metabolism & 0.00006 & 0.179 & $33 / 184$ \\
\hline Arginine and Proline Metabolism & 0.00006 & 0.136 & $24 / 177$ \\
\hline Pancreatic Adenocarcinoma Signaling & 0.00006 & 0.269 & $32 / 119$ \\
\hline ILK Signaling & 0.00007 & 0.238 & $46 / 193$ \\
\hline B-alanine Metabolism & 0.00012 & 0.194 & $18 / 93$ \\
\hline Glioma Invasiveness Signaling & 0.00012 & 0.333 & $20 / 60$ \\
\hline Colorectal Cancer Metastasis Signaling & 0.00019 & 0.218 & $56 / 257$ \\
\hline Inhibition of Angiogenesis by TSP1 & 0.00019 & 0.359 & $14 / 39$ \\
\hline Cell Cycle Control of Chromosomal Replication & 0.00021 & 0.387 & $12 / 31$ \\
\hline Bladder Cancer Signaling & 0.00022 & 0.283 & $26 / 92$ \\
\hline HIF1 Signaling & 0.00024 & 0.269 & $29 / 108$ \\
\hline Fcy Rece ptor-mediated Phagocytosis in Macrophages and Monocytes & 0.00025 & 0.265 & $27 / 102$ \\
\hline IL-8 Signaling & 0.00026 & 0.223 & $43 / 193$ \\
\hline TR/RXR Activation & 0.00068 & 0.260 & $25 / 96$ \\
\hline
\end{tabular}


specific pathway inhibition, and compared them to the human follicular carcinoma line FTC-133 (PTEN and p53 mutant), and the human ATC lines CAL-62 (KRAS and p53 mutant) and C643 (HRAS and p53 mutant). Onehour treatment with the AKT inhibitor MK-2206 $(0.5 \mu \mathrm{M})$ or with the MEK inhibitor U0126 $(10 \mu \mathrm{M})$ effectively abolished AKT and ERK1/2 phosphorylation in all cell lines (Figure 5C). The effect of both compounds on cell viability, measured by determining the $\mathrm{IC}_{50}$ after $72 \mathrm{~h}$ treatment, clearly correlated with the cell lines' genetic makeup, with Pten $^{-/}$cells being more sensitive to AKT inhibition than Pten $^{+/+}$cells, and Ras mutant cells more sensitive to MEK inhibition than cells with wild type Ras (Figure 5C).

Thus, although mouse ATCs display lower pAkt levels than coexisting well-differentiated tumor areas, they still depend on Akt signaling for their survival and proliferation.

Table 1: Top 50 genes deregulated $(\mathrm{FDR}<0.1)$ in both mouse and human ATC, ranked by expression level in mouse.

\begin{tabular}{|c|c|c|c|c|c|c|c|}
\hline \multirow{2}{*}{ MouseGene } & Hs 1 ATC & Hs 2 ATC & Mm ATC & \multirow{2}{*}{ MouseGene } & Hs 1 ATC & Hs 2 ATC & Mm ATC \\
\hline & \multicolumn{3}{|c|}{ Upregulated } & & \multicolumn{3}{|c|}{ Downregulated } \\
\hline *Timp1 & 4.699 & 5.213 & 21.086 & Patz1 & 0.436 & 0.216 & 0.293 \\
\hline *Steap1 & 3.760 & 14.778 & 10.021 & Suox & 0.729 & 0.297 & 0.291 \\
\hline${ }^{*} \operatorname{tg} a 5$ & 2.426 & 4.675 & 8.795 & Epb4.114b & 0.107 & 0.029 & 0.286 \\
\hline Kif20a & 2.221 & 22.184 & 7.664 & $\operatorname{Tn} x b$ & 0.581 & 0.264 & 0.285 \\
\hline Ccnb1 & 5.664 & 11.688 & 7.395 & Fxyd1 & 0.651 & 0.307 & 0.279 \\
\hline Ccna2 & 3.119 & 14.546 & 7.167 & Grb14 & 0.748 & 0.342 & 0.276 \\
\hline *Racgap1 & 7.247 & 15.876 & 6.938 & 1190002H23Rik & 0.252 & 0.212 & 0.274 \\
\hline Rrm2 & 10.807 & 51.614 & 6.860 & Slc5a3 & 0.220 & 0.153 & 0.273 \\
\hline *Prc1 & 5.295 & 26.946 & 6.491 & Ww c1 & 0.384 & 0.297 & 0.260 \\
\hline *TpX2 & 3.766 & 38.703 & 6.390 & Mettl7a1 & 0.090 & 0.050 & 0.257 \\
\hline Kif4 & 3.613 & 19.001 & 5.861 & Stxbp6 & 0.373 & 0.044 & 0.254 \\
\hline Cenpe & 2.001 & 13.520 & 5.749 & Tppp & 0.681 & 0.102 & 0.251 \\
\hline Cep55 & 4.075 & 26.077 & 5.707 & Acacb & 0.527 & 0.069 & 0.242 \\
\hline Kf 2c & 2.029 & 9.175 & 5.374 & Bspry & 0.364 & 0.050 & 0.237 \\
\hline Ccdc109b & 3.470 & 8.822 & 5.369 & Rbpms & 0.370 & 0.102 & 0.232 \\
\hline Plau & 5.606 & 46.647 & 5.363 & Cds 1 & 0.516 & 0.057 & 0.217 \\
\hline Depdc1a & 1.771 & 7.384 & 5.303 & Nebl & 0.112 & 0.019 & 0.210 \\
\hline Bub1b & 3.180 & 20.421 & 5.246 & Car4 & 0.273 & 0.053 & 0.203 \\
\hline Basp1 & 3.274 & 8.466 & 5.114 & ${ }^{*} \mathrm{Nkx} 2-1$ & 0.147 & 0.016 & 0.200 \\
\hline Asf1b & 1.904 & 4.015 & 4.831 & Pdk2 & 0.646 & 0.474 & 0.188 \\
\hline Dtl & 3.446 & 5.716 & 4.782 & Bex1 & 0.178 & 0.025 & 0.182 \\
\hline Tyrobp & 4.242 & 19.675 & 4.652 & Sorbs2 & 0.094 & 0.013 & 0.181 \\
\hline Cdca8 & 1.837 & 6.322 & 4.577 & Cldn3 & 0.125 & 0.027 & 0.180 \\
\hline Ren1 & 3.697 & 2.780 & 4.547 & Sall1 & 0.287 & 0.018 & 0.180 \\
\hline Cenpa & 1.714 & 3.183 & 4.503 & Prkcq & 0.432 & 0.134 & 0.180 \\
\hline Foxm 1 & 3.121 & 7.703 & 4.434 & *Duox2 & 0.107 & 0.015 & 0.178 \\
\hline Nusap1 & 3.727 & 17.416 & 4.385 & Rragd & 0.222 & 0.163 & 0.174 \\
\hline Dlgap5 & 2.449 & 22.229 & 4.359 & Smad9 & 0.691 & 0.024 & 0.173 \\
\hline Gpsm2 & 2.351 & 2.026 & 4.339 & Fabp4 & 0.102 & 0.020 & 0.168 \\
\hline C3ar1 & 2.891 & 15.589 & 4.170 & Pygm & 0.733 & 0.605 & 0.164 \\
\hline Kntc1 & 1.534 & 7.468 & 4.146 & Gpr56 & 0.166 & 0.092 & 0.161 \\
\hline Stil & 1.787 & 6.955 & 4.098 & Rap1gap & 0.143 & 0.028 & 0.157 \\
\hline Ncaph & 1.652 & 4.310 & 4.088 & Erbb4 & 0.583 & 0.157 & 0.150 \\
\hline Zwilch & 2.346 & 6.767 & 4.050 & Bex4 & 0.323 & 0.148 & 0.149 \\
\hline Atad2 & 1.928 & 2.755 & 4.000 & $\mathrm{Glb} 1 / 2$ & 0.462 & 0.270 & 0.148 \\
\hline Fabp5 & 7.508 & 4.293 & 3.954 & Ager & 0.683 & 0.392 & 0.144 \\
\hline Cks2 & 9.287 & 26.933 & 3.911 & Lrp2 & 0.276 & 0.012 & 0.133 \\
\hline Tubb6 & 4.194 & 4.191 & 3.839 & Ocln & 0.650 & 0.174 & 0.124 \\
\hline Cdc20 & 5.251 & 35.621 & 3.822 & Myo5c & 0.181 & 0.046 & 0.112 \\
\hline Melk & 5.470 & 15.689 & 3.765 & Bcam & 0.389 & 0.246 & 0.107 \\
\hline Ttk & 3.254 & 22.640 & 3.702 & Fam13a & 0.304 & 0.124 & 0.094 \\
\hline Aurkb & 1.639 & 2.222 & 3.661 & Id4 & 0.050 & 0.009 & 0.091 \\
\hline Csf2rb & 2.201 & 22.256 & 3.632 & Fam189a2 & 0.170 & 0.015 & 0.083 \\
\hline Cdkn3 & 4.688 & 16.665 & 3.625 & Cdh16 & 0.305 & 0.058 & 0.077 \\
\hline Ube2c & 4.383 & 46.951 & 3.621 & ${ }^{*}$ Ppargc1a & 0.362 & 0.055 & 0.069 \\
\hline Fcgr2b & 2.191 & 15.069 & 3.561 & ${ }^{*} \mathrm{Pax} 8$ & 0.095 & 0.014 & 0.063 \\
\hline Trip13 & 2.555 & 14.673 & 3.418 & ${ }^{*} \mathrm{Tg}$ & 0.011 & 0.001 & 0.061 \\
\hline Ncapg2 & 2.384 & 7.484 & 3.407 & $\overline{\mathrm{Kcnj}} 16$ & 0.034 & 0.003 & 0.045 \\
\hline Mad211 & 5.281 & 15.378 & 3.398 & ${ }^{*}$ Tshr & 0.029 & 0.005 & 0.045 \\
\hline Mcm3 & 1.584 & 2.853 & 3.366 & ${ }^{*} \mathrm{Tpo}$ & 0.039 & 0.003 & 0.036 \\
\hline
\end{tabular}




\section{A "mitotic gene signature" in mouse and human ATCs}

To gain insight into the molecular characteristics of ATCs developed by [Pten, $p 53]^{\text {thyr }-/}$ mice, we performed genome-wide expression profiling using the Affymetrix platform on thyroids from 3-month old control, single, and double mutant mice, as well as on five follicular and five anaplastic carcinomas developed by $P t e n^{\text {thyr }-}$ and

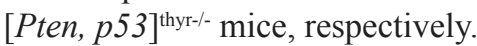

As predicted by the inability of thyroid-specific $p 53$ deletion to yield an overt phenotype, a heat map including all probes with more than a 5 -fold change across any of the six groups showed that $p 53^{-1-}$ thyroids cluster together with those of wild type mice (Figure 6A). Similarly, no remarkable differences were apparent between the transcriptomes of Pten ${ }^{\text {thyr }-/}$ and [Pten, $\left.p 53\right]^{\text {thyr- }- \text { t }}$ thyroids. On the contrary, the profile of [Pten, p53 $]^{\text {thyr }-/}$ ATCs (810 months of age) was strikingly different from that of younger [Pten, $p 53]^{\text {thyr-/ }}$ mice and also from that of welldifferentiated follicular carcinomas developed by aging Pten $^{\text {thyr-/ }}$ mice (16-20 months). These data strongly suggest that the molecular events leading to the development and maintenance of ATC are unique to this tumor type and that characterization of these changes could uncover clinically relevant pathways and targets.

Overall, using a stringent false discovery rate (FDR) of $5 \%, 2,960$ genes were found deregulated \pm 2 -fold in ATC samples, compared to wild type thyroids (1,395 up, and 1,565 down). To identify biological processes significantly impacted by ATC development, we performed canonical pathway enrichment using Ingenuity Pathway Analysis (IPA). Significant enrichment was observed in pathways involved in metabolic remodeling of the tumors, in cell motility and invasiveness, in leukocyte recruitment and function, and in epithelial-mesenchymal transition (Table 1).

In order to determine to what extent the gene expression changes uncovered in $[\text { Pten, } p 53]^{\text {thyr- }-}$ ATCs overlap with those identified in human anaplastic carcinomas, we retrieved from the GEO and EBI repositories two datasets containing gene expression data from a total of six control thyroids and eight ATCs. Since these two available datasets had been generated using two different Affymetrix platforms [24, 25], we analyzed them separately. After adjusting for a false discovery rate $<10 \%$ and for genes present in all three platforms, we identified 430 genes that were simultaneously deregulated in all three datasets (Figure 6B and Table 2). An additional 1321
Timp1

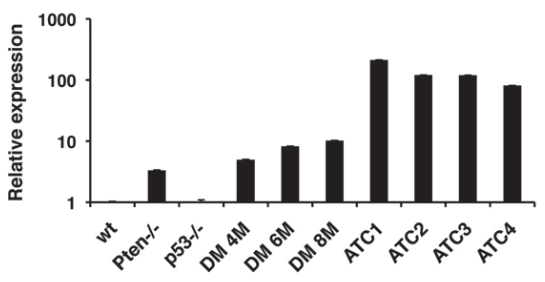

Racgap1

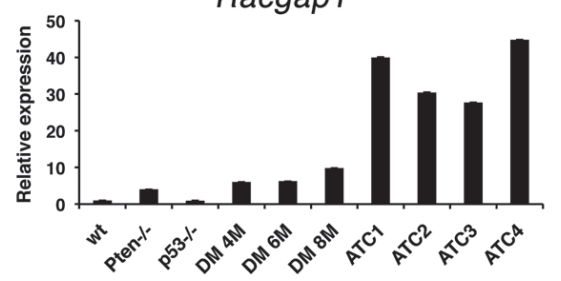

Ppargc1a

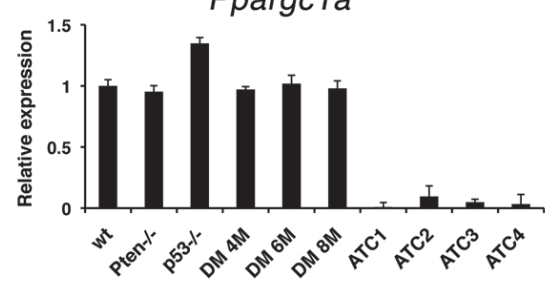

Steap1

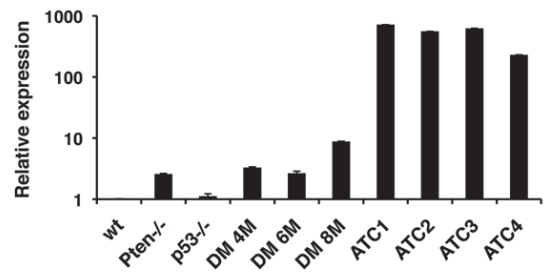

Prc1

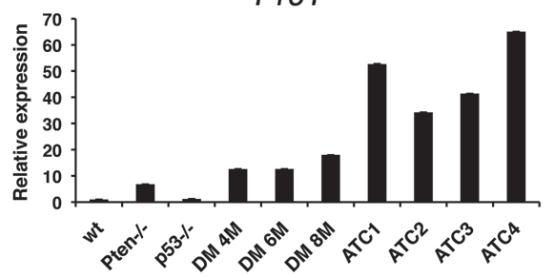

Itga5

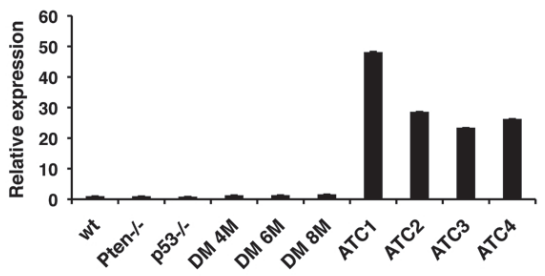

$\operatorname{Tpx2}$

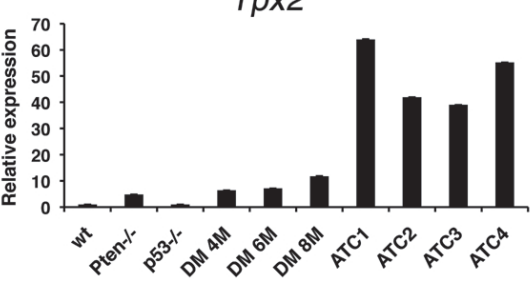

Figure 7: Real-time PCR validation of a panel of genes differentially regulated in both mouse and human ATCs in 4-month old control and single mutant mice, ATC-free, progressively older $(4,6,8$ months) double mutants, and histologically confirmed ATCs from 8- to 9-month old double mutants. 
genes were co-deregulated in mouse ATCs and in at least one human dataset.

Strikingly, 24 of the top 50 common up-regulated genes encode for proteins involved in the control of the $\mathrm{G} 2 / \mathrm{M}$ transition and of the mitotic process (Table 2 , bold), indicating that mitotic deregulation is a key process in the development of ATC, and thus identifying putative clinically valuable targets. As expected, the list of common down-regulated genes contains several thyroid differentiation markers (Table 2, underlined), underlining the dramatic loss of differentiation that characterizes the development of anaplastic thyroid tumors.

To further investigate the 430-gene ATC signature identified by the interspecies analysis, we used Gene Set
Enrichment Analysis (GSEA) to query the Molecular Signatures Database (MSigDB), a large collection of curated gene sets [26]. One hundred-nineteen gene sets were enriched in both mouse and human ATCs with an FDR of less than $10 \%$. This included sets of genes up- and down-regulated in anaplastic thyroid carcinoma compared to normal thyroid tissue [27] as well as three independent sets for mitosis-related genes (Figure 6C).

We next used real time PCR to validate a subset of the deregulated genes (marked with an asterisk in Table 2) using an independent set of tissues from control, single mutant, and progressively older double mutant mice, and histology-confirmed ATCs. Dramatic overexpression of the top three genes (ranked based on
A

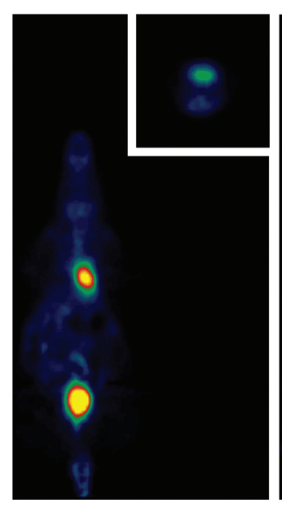

wt

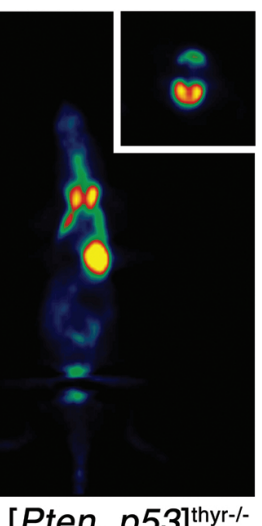

$[\text { Pten, p53 }]^{\text {thyr-/- }}$

$\mathrm{C}$

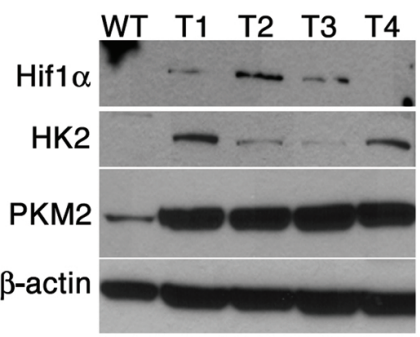

$\mathrm{D}$

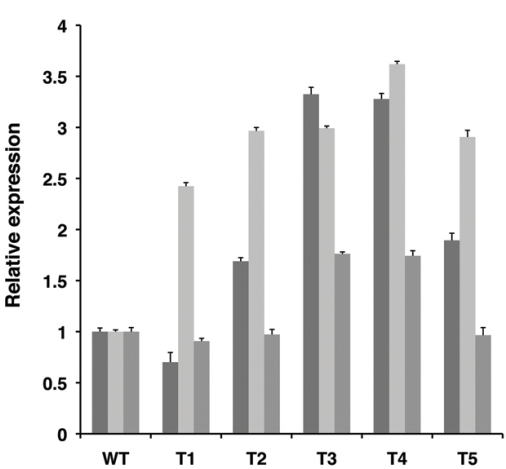

B
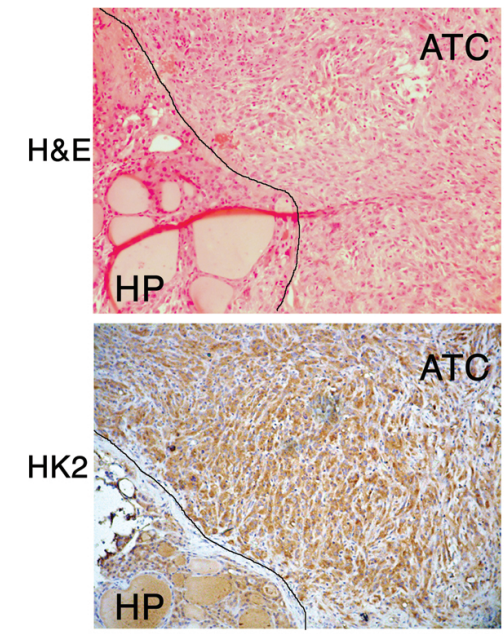

PKM2

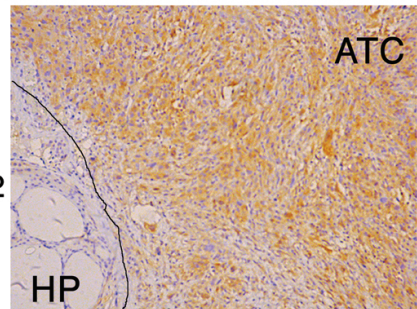

E

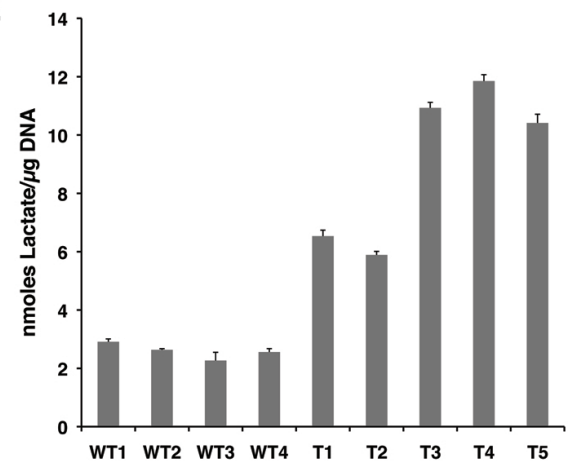

Figure 8: Mouse ATCs undergo a glycolytic switch (Warburg effect). (A) Coronal section (transverse in the inset) of representative ${ }^{18}$ FDG PET scans of 8-month old control and compound mutant mice, showing high ${ }^{18}$ FDG accumulation in the thyroid tumor. (B) H\&E and immunohistochemical detection of Hexokinase II and Pyruvate kinase M2 in the anaplastic component of a representative mouse tumor. The line demarcates the boundary between well-differentiated and anaplastic component. (C) Western blotting showing the increased expression of Hif1 $\alpha$, Hexokinase II and Pyruvate kinase M2 in four mouse ATCs (T1-T4). (D) Real-time PCR analysis of the expression of Hexokinase II, Pyruvate kinase M2, and Lactate dehydrogenase A in five mouse ATCs (T1-T5). (E) Lactate content of four wild type thyroids and five ATCs (T1-T5), showing consistent increase in neoplastic glands. 
expression levels in mouse samples), i.e. Timp1, Steap1, and Itga5, was confirmed in mouse ATCs compared to wild type controls, single mutants, and aging double mutants (Figure 7). The expression of Timp1, an inhibitor of matrix metalloproteinases that promotes mitogenesis and angiogenesis, and previously found up-regulated in thyroid cancer [28] and of Steap1, a cell surface protein found over-expressed in various cancers [29] was already increased (although at a lower level) in Pten $^{\text {thyr- }- \text { - }}$ mice, suggesting a direct role of PI3K signaling in their regulation. Conversely, Itga5 expression was increased only in ATCs, indicating that integrin $\alpha 5$ may play an active role in the establishment and maintenance of epithelial-tomesenchymal transition [30]. We also validated the overexpression of Racgap1, Prc1, and Tpx2, which belong to the large group of genes involved in the control of mitosis [31-33]. Validation of the down-regulation of several thyroid differentiation markers is shown in Figure 2. In addition, we validated the striking repression of Ppargcla,

the gene encoding for the transcriptional coactivator PGC1- $\alpha$, which integrates mitochondrial biogenesis and energy production with various cellular functions [34].

\section{Mouse ATCs exhibit a glycolytic switch}

Many tumors are characterized by a shift from an oxidative to a glycolytic bioenergetic pathway, a phenomenon known as the Warburg effect [35]. Human ATCs commonly display intense glucose uptake on ${ }^{18}$ F-FDG PET imaging, indicating that this tumor type has a strong glycolytic phenotype [36].

The down-regulation of Ppargcla prompted us to test whether the ATCs developing in [Pten, p53 $]^{\text {thyr- }- \text { - }}$ mice reflect this metabolic shift. We performed ${ }^{18} \mathrm{~F}-\mathrm{FDG}$ PET imaging on sex- and age-matched control and ATCbearing mice (8-month old), and found that tumor-bearing $[\text { Pten, } p 53]^{\text {thyr-/- }}$ mice avidly uptake radiolabeled glucose

B
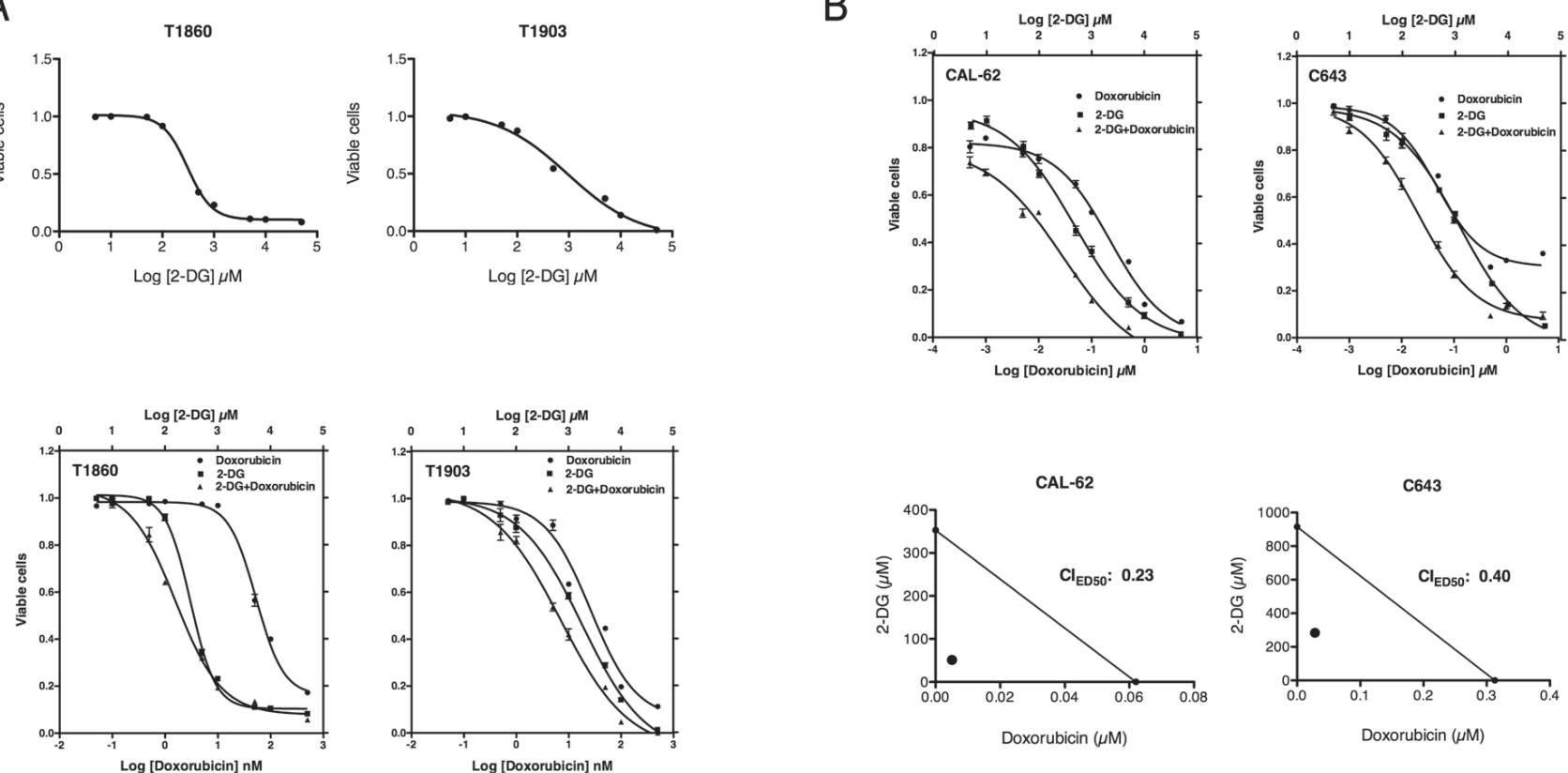

C
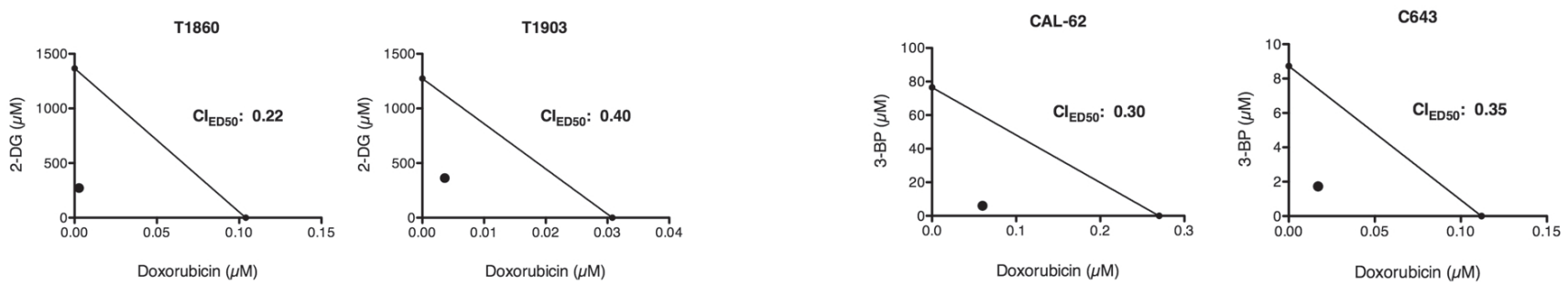

Figure 9: Both mouse and human ATC cell lines are highly sensitive to glycolytic inhibitors. (A) Top panel: doseresponse curves showing the effect of 2-deoxyglucose (2-DG) on the viability of two mouse ATC cell lines. Middle panel: dose-response curves showing the. Bottom panel: isobolograms showing strong synergy between the two compounds. (B) Top panel: dose-response curves showing the cooperative effect of a 2-DG/Doxorubicin combination on the viability of two human ATC cell lines. Middle panel: isobolograms showing strong synergy between the two compounds. (C) Isobolograms showing strong synergy between doxorubicin and another glycolytic inhibitor, 3-bromopyruvate (3-BP). 
(Figure 8A). Furthermore, immunohistochemical, western blotting, and real time PCR approaches revealed that ATCs developing in [Pten, $p 53]^{\text {thyr-/ }}$ mice consistently upregulate Hifl $\alpha$, Hexokinase 2, and Pyruvate Kinase M2, all of which have been shown to be directly responsible for the establishment of the Warburg effect (Figure 8B-D). Although Ldha, the gene encoding Lactate Dehydrogenase A, was not consistently up-regulated in mouse ATCs, we found that lactate content of every tumor tested was dramatically increased (up to four-fold) compared to control thyroids, further demonstrating the highly glycolytic nature of these tumors (Figure 8E).

\section{Mouse and human ATC cell lines are sensitive to glycolytic inhibitors}

Based on these results, we tested whether the glycolytic inhibitor 2-deoxyglucose (2-DG), a glucose analogue which is phosphorylated by hexokinase but cannot be further metabolized in the glycolytic process [37], would affect the growth and survival of two cell lines we established from ATCs developed by [Pten, $p 53]$ thyr- - mice. Both cell lines were efficiently inhibited by 2-DG, showing dose-dependent growth suppression at $48 \mathrm{~h}$ with an $\mathrm{ED}_{50}(0.3 \mathrm{mM}$ for $\mathrm{T} 1860$ and $1.8 \mathrm{mM}$ for T1903) remarkably lower than previously reported (6.7$8.1 \mathrm{mM}$ ) for prostate and breast cancer cell lines [37] (Figure 9A, top panels), suggesting that ATC cells might be especially sensitive to glycolysis inhibition. However, glycolytic inhibitors as single agents have shown limited efficacy in vivo [38], while their combination with standard chemotherapy has shown, in some instances, a promising synergistic effect $[38,39]$. Thus we tested whether 2-DG could enhance the cytotoxic effect of doxorubicin, a standard, although poorly effective, treatment for ATC. We compared the single agent dose-response curves of the two aforementioned mouse ATC cell lines to the curve obtained using the two drugs combined at a fixed ratio based on the most effective single dose concentration for each drug. The combination treatment was more effective than each single agent over a wide range of concentrations (Figure 9A, middle panels). In order to establish whether the combined effects of 2-DG and doxorubicin were synergistic rather than additive, we calculated the combination index (CI) according to the well-established Chou and Talalay median effect method [40]. Figure 9A (bottom panel) shows the isobolograms for the drug combinations in the two cell lines, and the calculated CIs for the $\mathrm{ED}_{50}$. Strong synergistic effects $(\mathrm{CI}<1)$ resulted from the combination of 2-DG and doxorubicin.

Next, we extended these findings to two human ATC cell lines, CAL-62 and C643, characterized by different driver mutations compared with our mouse model. CAL62 harbors a G12R KRAS mutation, while C643 harbors a
G13R HRAS mutation [41]. In addition, p53 is inactivated in both cell lines, consistent with most ATCs [42].

Both human ATC cell lines responded to 2-DG in a manner similar to the mouse cells, with an $\mathrm{ED}_{50}(0.48$ $\mathrm{mM}$ for CAL-62, $1.19 \mathrm{mM}$ for C643) again lower than previously reported for other tumor types (Figure 9B, top panels). Doxorubicin alone was more effective in CAL62 than in C643. When combined in a fixed ratio, the two drugs displayed a striking increase in efficacy at all concentrations tested, and the CI calculation confirmed the strongly synergic nature of this interaction (Figure 9B, bottom panels).

To conclusively demonstrate that inhibition of glycolysis can effectively synergize with standard chemotherapy in ATC, we used a second glycolysis inhibitor, 3-bromopyruvate (3-BP), an alkylating agent that inhibits hexokinase and GAPDH [43]. Since 3-BP has a Ki for glycolysis inhibition of $2.4 \mathrm{mM}$, while the one for DG is $15.5 \mathrm{mM}$, 3-BP appears to be a more efficient glycolysis inhibitor than 2-DG [44]. When combined with doxorubicin, 3-BP showed a strong synergistic effect, with a CI of 0.3 (Figure 9C).

Taken together, these data strongly suggest that anaplastic thyroid carcinomas are highly sensitive to glycolysis inhibitors, especially in combination with cytotoxic chemotherapy, independent of the nature of the driver mutation originally responsible for the transformation process.

\section{DISCUSSION}

The prevalence of thyroid cancer is increasing worldwide, and this is due only in part to improved and earlier detection [45]. Although less than 5\% of the 48,020 new thyroid cancer cases $(+7.5 \%$ compared to 2010) estimated for 2011 in the United States [46] will be diagnosed as anaplastic tumors, the latters will account for the majority of the 1,740 estimated annual deaths. The dismal prognosis associated with these tumors reflects their intrinsic resistance to any therapeutic approach, including surgery, radiation, chemotherapy, and targeted therapy [6]. The genomic instability and karyotypic complexity that characterize ATCs [12] are likely major determinants of therapy resistance, since they result in the simultaneous activation of multiple oncogenic pathways, and thus in the establishment of a redundant network offering multiple escape and survival routes. All our current knowledge on the pathogenetic mechanisms of ATC is based on the analysis of patient material and on the use of cell lines and xenograft models. It is thus clear that an in vivo, immunocompetent, and clinically relevant model of ATC would be a critical tool to better understand the mechanisms associated with ATC development, and to identify novel, more effective therapeutic targets.

Most ATCs harbor mutations that activate one of two pathways that act as drivers of the transformation process: 
the RAS/BRAF/MAPK cascade, and the PI3K/PTEN/ AKT cascade [47]. These mutations are usually already present in the well-differentiated tumor component from which most ATCs develop [3, 4]. In addition, most ATCs share inactivating mutations of $p 53$, which are likely to determine, in combination with the driver mutations, the anaplastic features of these tumors [48].

Building upon these patient-derived genetic data, we have generated the first mouse model of ATC by combining, in the mouse thyroid follicular cells, p53 loss with constitutive PI3K activation, via deletion of the Pten tumor suppressor.

The most clinically relevant feature of this model is the remarkable similarity of its morphological and molecular features to human ATCs, including those tumors that do not display PI3K activation. [Pten, p53 $]^{\text {thyr-/- }}$ anaplastic tumors derive from pre-existing follicular carcinomas, and exhibit cellular pleomorphism, aneuploidy, genomic instability, and epithelial-to-mesenchymal transition. This latter feature is of particular interest, since recent data in the breast and other tissues suggest that EMT is linked to the generation of a cancer-initiating cell (or cancer stem cell) population $[49,50]$, endowed with an intrinsic drug resistance phenotype [51]. Ongoing studies in this model will shed more light on the signals and mechanisms that initiate and maintain this phenotype.

The expression of all the classical thyroid-specific markers, including that of the sodium-iodide symporter (NIS), is lost as a consequence of the de-differentiation process. Thus this model provides us with a novel in vivo tool to explore the mechanisms leading to NIS suppression, and to attempt to pharmacologically restore radioiodine sensitivity, as recently described in a model of papillary and poorly differentiated $B R A F^{\mathrm{V} 600 \mathrm{E}}$-dependent thyroid carcinoma [52].

Another important and clinically relevant feature of our model, underlining its high similarity to human tumors, is the absence of the dramatic TSH increase typical of all current mouse models of advanced thyroid cancer, a phenotype that is never seen in human patients $[15,18$, 52]. The possible confounding effects of high TSH levels during the transformation process are underlined by the absence of neoplastic transformation when these models are crossed to $T s h r^{-/}$mice $[17,53]$.

Despite the simultaneous loss of Pten and p53, it still takes at least 6 months for these mice to develop frank carcinomas, which might suggest the need for additional genetic alterations to accumulate. Our data exclude the presence of mutations in the hotspots of known ATCrelated genes (Braf, $\mathrm{H}_{-}, \mathrm{N}_{-}$, and $\mathrm{Kras}$ ), and indicate that a thorough, genome-wide approach to identify possible additional cooperating events is warranted.

A noteworthy feature, with important clinical implications, is that although ATCs are aneuploid and genomically instable, and thus resistant to single agent approaches, still they are somewhat addicted to their original driver mutation. In fact, a well characterized AKT inhibitor, MK-2206, was much more effective on cell lines derived from murine $[\text { Pten, } p 53]^{\text {thyr }-/}$ anaplastic tumors than on human cell lines harboring $R A S$ mutations. Although this notion will need additional in-depth validation, it might represent a valid rationale for the use of driver pathway-targeted inhibitors in combination with cytotoxic drugs.

Further support to the clinical relevance of this model comes from the analysis of its molecular features. Expression profiling of control, single, and double mutant thyroid glands, compared with follicular and anaplastic tumors developed by Pten $^{\text {thyr- }- \text { and }}$ [Pten, $p 53$ ] thyr-/ mice respectively, revealed a substantial similarity between $P t e n^{\text {thyr- } /-}$ and $[\text { Pten, p53 }]^{\text {thyr-/- }}$ hyperplasias and $P_{t e n}{ }^{\text {thyr-/ }}$ follicular carcinomas, emphasizing the driver role of PI3K activation in the establishment of neoplastic transformation. Strikingly, ATC profiles were significantly different from any other sample, including younger $[\text { Pten, p53 }]^{\text {thyr- } / \text { - }}$ compound mutants, underlining the existence of a dramatic biological switch associated with the establishment of anaplasia and EMT. Molecular characterization of this switch will undoubtedly yield much-needed clues on potential therapeutic targets along the pathways involved. While the biological features of ATCs predicted an enrichment in genes involved in pathways related to EMT, invasion, and metastasis, it is interesting that we also found significant alterations in groups of genes associated with metabolic pathways, such as Propanoate metabolism, Urea cycle, and Arginine and proline metabolism, that have been recently associated with a neoplastic state [54].

Analysis of the overlap between genes significantly deregulated in our mouse model and those deregulated in the only two Affymetrix-based, publicly available, datasets containing human ATCs [24, 25] has allowed us to define a set of 430 genes consistently and significantly deregulated in both mouse and human ATCs. Strikingly, this "ATC signature" is highly enriched in genes encoding proteins involved in the control of mitosis, and shows a considerable overlap with the "cell proliferation and chromosomal instability signature" reported by Salvatore et al. using a different platform [12]. The availability of novel, specific inhibitors of key mitotic kinases such as Aurora A [55] and Plk1 [56] emphasizes the clinical relevance of this finding, and, together with preliminary reports showing efficacy of Plk1 inhibition in ATC cell lines [57], warrants further studies in ATC models using these compounds alone or, more likely, in combination with other relevant drugs.

Finally, we have provided evidence that, similar to human ATCs, [Pten, p53 $]^{\text {thyr-/- }}$ tumors are highly glycolytic and very sensitive to two compounds, 2-DG and 3-BP, targeting different steps of glycolysis. Despite a growing literature supporting the efficacy of anti-glycolytic compounds in cancer cell lines $[37,39,58]$ as well as in 
xenograft models [38, 44], their clinical development as single agents has been slowed down by toxicity-related issues associated with prolonged administration of high concentrations of these drugs. However, promising results have been obtained in clinical trials using 2-DG as a radiosensitizer [59]. More specific inhibitors, with the goal of widening their therapeutic window, are currently under development [60]. Our data support the notion that glycolysis inhibitors not only decrease proliferation and survival of ATC cells as single agents at a relatively low concentration, but also significantly increase the efficacy of a cytotoxic drug, doxorubicin, already in clinical use for ATC. The rationale for this combination is twofold: i) DNA damage caused by doxorubicin cannot be effectively repaired when the cell's ATP levels are reduced upon glycolytic inhibition; ii) reduced ATP will decrease the efficacy of the ATP-dependent pumps responsible for the efflux of doxorubicin from the cells. Thus, our proof-ofprinciple data provide a strong rationale to develop and test additional combinations of novel glycolytic inhibitors and clinically relevant chemotherapeutic drugs in sensitive tumor types, such as ATC, for which current therapeutic approaches invariably fail.

\section{METHODS}

\section{Animals}

The Pten ${ }^{L / L}$ and TPO-Cre strains have been described [22]. All strains were backcrossed in the $129 \mathrm{~Sv}$ background for at least eight generations, and littermates were used as controls.

\section{Hormone measurements}

Blood was collected by cardiac puncture. Serum thyroid-stimulating hormone (TSH) was measured using a sensitive, heterologous, disequilibrium double-antibody precipitation RIA [61], and results were expressed in mU/ liter. All samples were individually analyzed for each mouse. Total T4 concentrations were measured by a solidphase RIA (Coat-a-Count; Diagnostic Products Corp., Los Angeles, CA) adapted for mice. Values of the respective limits of assays sensitivities were assigned to samples with undetectable TSH and T4 concentration.

\section{Immunohistochemistry}

$6 \mu \mathrm{m}$ sections were subjected to antigen retrieval, incubated with pERK1/2 (Thr202/Tyr204), pAKT (Ser473), pSmad2 (Ser465/467), Vimentin, e-Cadherin, HK2, and PKM2 antibodies (Cell Signaling, Danvers, MA) and counterstained with hematoxylin.

\section{Establishment and maintenance of cell lines}

Primary thyroid tumors were minced and resuspended in Ham's F12/10\% FBS with $100 \mathrm{U} / \mathrm{ml}$ type I collagenase (Sigma, St. Louis, MO) and $1 \mathrm{U} / \mathrm{ml}$ dispase (Roche, Indianapolis, IN). Enzymatic digestion was carried out for $90 \mathrm{~min}$ at $37^{\circ} \mathrm{C}$. After digestion, cells were seeded in Ham's F12 containing 40\% Nu-Serum IV (Collaborative Biomedical, Bedford, MA), gly-his-lys (10ng/ml, Sigma), and somatostatin $(10 \mathrm{ng} / \mathrm{ml}$, Sigma) and allowed to spread and reach confluence before being passaged. After the fourth passage, tumor cells were adapted to grow in DMEM/10\%FBS.

\section{Mutation detection}

Genomic DNA was isolated from cell lines established from primary tumors and subjected to PCR to amplify fragments suitable for sequencing [62]. PCR products were gel purified and sequenced from both ends.

\section{Metaphase preparation and chromosome analysis}

For chromosome preparation, primary cells at passage p1-p3 were plated in a $35 \mathrm{~mm}$ Petri dish and incubated with Colcemid (Sigma Aldrich, St. Louis, MO) at a concentration of $10 \mathrm{ng} / \mathrm{ml}$ over night or for $3 \mathrm{hrs}$ at $100 \mathrm{ng} / \mathrm{ml}$. Chromosomes were extracted with standard hypotonic treatment $(0.075 \mathrm{M} \mathrm{KCl})$, dropped on microscope slides and mounted with antifade containing DAPI (Invitrogen, Carlsbad, CA). Slides were imaged on a Zeiss Axiovert 200 Microscope using a DAPI filter (Chroma Technologies, Bellows Falls, VT). Ten fields were selected randomly and 15 to 30 cells for each tumor line were subjected to chromosome count and visually inspected for the presence of gross chromosome abnormalities and chromosome fragments.

\section{Western blot analysis}

Thyroids and cells were homogenized on ice in RIPA buffer supplemented with Complete protease inhibitor tablet (Roche Diagnostics, Indianapolis, IN). Western blot analysis was carried out on $20-40 \mu \mathrm{g}$ proteins using phospho-antibodies from Cell Signaling (Danvers, MA) and a $\beta$-actin antibody from Sigma-Aldrich.

\section{Drug treatments}

Pharmacological inhibitors of AKT (MK-2206, Selleck Chemicals), and MEK1/2 (U0126, Cell Signaling) were added $24 \mathrm{~h}$ after plating, in sextuplicate. After $72 \mathrm{~h}$, 
viability was assessed using the Wst-1 assay (Takara) and IC50s were determined using Prism software.

\section{Real time PCR}

Total RNA was extracted with Trizol and reverse transcribed using the Thermoscript kit (Invitrogen). qRTPCR was performed on a StepOne Plus apparatus using the Absolute Blue qPCR Rox Mix (Thermo Scientific, Waltham, MA) and TaqMan expression assays (Applied Biosystems, Carlsbad, CA). Each sample was run in triplicate and Ipo 8 was used to control for input RNA. Data analysis was based on the $\mathrm{Ct}$ method, and experiments were repeated at least three times using at least two independent organ pools (at least five mice/pool).

\section{Expression profiling}

Three pools of three to five mice, and five individual, flash-frozen, histologically verified tumor samples of each histotype, were randomly selected from each of the six different groups (control, Pten ${ }^{\text {thyr- }-}, p 53^{\text {thyr- }-},[\text { Pten, } p 53]^{\text {thyr- }}$ ', follicular carcinomas, anaplastic carcinomas). Tumor fragments and thyroid glands were subjected to total RNA isolation using TRIzol Reagent (Invitrogen) followed by further purification with the RNAeasy Kit (Qiagen). Total RNA quality was verified using the Agilent Bioanalyzer 2100. Microarray hybridization was performed at the Albert Einstein Genomics Facility using Affymetrix Mouse Gene 1.0 arrays. Normalization and background subtraction were performed with RMA, using the "oligo" package of Bioconductor. Gene selection was performed using the "limma" package. Raw p values were corrected for multiple testing using a "false discovery rate" $<0.05$. Microarray data were deposited in GEO (accession no. GSE30427).

\section{Canonical Pathway Analysis}

Canonical pathways analysis identified the pathways from the Ingenuity Pathways Analysis library of canonical pathways that were most significant to the data set. Molecules from the data set that met the \pm 2 -fold cutoff with a FDR $<0.05$ and were associated with a canonical pathway in Ingenuity's Knowledge Base were considered for the analysis. The significance of the association between the data set and the canonical pathway was measured in 2 ways: 1) A ratio of the number of molecules from the data set that map to the pathway divided by the total number of molecules that map to the canonical pathway. 2) Fisher's exact test was used to calculate a p-value determining the probability that the association between the genes in the dataset and the canonical pathway is explained by chance alone.

\section{Interspecies analysis}

Two human datasets were obtained from GEO (E-GEOD-27155: 4 normal vs. 4 ATC) and EBI (E-MEXP-2442: 2 normal vs. 4 ATC). The mouse dataset (see above) contained six independent wild type pools and 5 individual ATCs. .CEL files were processed and normalized using the RMA function and the "affy" and "oligo" packages of Bioconductor. Data for each experiment were normalized separately, due to the different Affymetrix platforms used in the three experiments. Gene selection for each experiment was done using the "limma" package. Raw $\mathrm{p}$ values were corrected for multiple testing using a "false discovery rate" $<0.1$. Top tables were generated for all probe-sets for each experiment. Humanmouse homology mapping file were obtained from the MGI database (ftp.informatics.jax.org/pub/reports/HMD HGNC Accession.rpt) and 11,508 genes common to all three datasets were selected.

\section{Lactate assay}

Lactate levels were assayed using a commercially available kit (Biovision, Mountain View, CA). Lactate levels were normalized to the amount of DNA extracted from each tissue fragment.

\section{$\left[{ }^{18}\right.$ F]Fluorodeoxyglucose positron emission tomography imaging}

Wild type and [Pten, $p 53]^{\text {thyr- }- \text { mice }}$ were fasted overnight before a tail vein injection of $\left[{ }^{18} \mathrm{~F}\right]$ fluorodeoxyglucose $(300 \mu \mathrm{Ci})$. One hour after injection, mice were subjected to positron emission tomography (PET) scanning with the Concorde Microsystems R4 microPET Scanner. Animals were imaged while anesthetized through inhalation with isoflurane. Image acquisition was done using the MicroPET Manager with the ASPIRO dedicated software.

\section{Chemotherapic treatments}

Doxorubicin (Sigma) and glycolytic inhibitors, 3-Bromopyruvate and 2-Deoxyglucose (Sigma) were added $24 \mathrm{~h}$ after plating, in quadruplicate. After $48 \mathrm{hs}$ cell viability was assessed using the Wst-1 assay (Roche). Preliminary experiments were conducted to ensure that, in the conditions used for these assays, this method yields the same results as direct cell counting (both trypan bluebased and automated). 


\section{Analysis of synergy}

Doxorubicin was combined with each of the different glycolytic inhibitors at a fixed ratio $(1: 1)$ of the individual IC90 concentrations of each drug. Drug combinations were then serially diluted. Statistical analysis of drug synergy was evaluated from the results of the Wst- 1 assays and calculated using the Chou-Talaly method [40] and the Calcusyn Software (Biosoft). To determine synergy between two drugs, the software uses a median-effect method that determines if the drug combination produces greater effects together than expected from the summation of their individual effects. The combination index (CI) values are calculated for the different dose-effect plots (for each of the serial dilutions) based on the parameters derived from the median-effect plots of the individual drugs or drug combinations at the fixed ratios. The CI was calculated based on the assumption of mutually nonexclusive drug interactions. CI values significantly > 1 are antagonistic, not significantly different than 1 are additive, and values $<1$ are synergistic.

\section{Statistical analysis}

Experiments were performed at least three times. Data were analyzed using the JMP 5.1, Calcusyn, and Prism software packages. Differences with P-values $<0.05$ were considered statistically significant.

\section{ACKNOWLEDGMENTS}

This work was supported by the Albert Einstein Cancer Center Core Grant, and by NIH grants to ADC (CA97097 and CA128943) and SR (DK15070 and DK20595). ADC is a recipient of the Irma T. Hirschl Career Scientist Award.

\section{REFERENCES}

1. Enewold L, Zhu K, Ron E, Marrogi AJ, Stojadinovic A, Peoples GE, Devesa SS. Rising thyroid cancer incidence in the United States by demographic and tumor characteristics, 1980-2005. Cancer Epidemiol Biomarkers Prev. 2009; 18:784-791.

2. Burns WR, Zeiger MA. Differentiated thyroid cancer. Semin Oncol. 2010; 37:557-566.

3. Wang HM, Huang YW, Huang JS, Wang CH, Kok VC, Hung CM, Chen HM, Tzen CY. Anaplastic carcinoma of the thyroid arising more often from follicular carcinoma than papillary carcinoma. Ann Surg Oncol. 2007; 14:30113018.

4. Quiros RM, Ding HG, Gattuso P, Prinz RA, Xu X. Evidence that one subset of anaplastic thyroid carcinomas are derived from papillary carcinomas due to BRAF and p53 mutations. Cancer. 2005; 103:2261-2268.

5. Cornett WR, Sharma AK, Day TA, Richardson MS, Hoda RS, van Heerden JA, Fernandes JK. Anaplastic thyroid carcinoma: an overview. Curr Oncol Rep. 2007; 9:152-158.

6. Wein RO, Weber RS. Anaplastic thyroid carcinoma: palliation or treatment? Curr Opin Otolaryngol Head Neck Surg. 2011.

7. Patel KN, Shaha AR. Poorly differentiated and anaplastic thyroid cancer. Cancer Control. 2006; 13:119-128.

8. Perri F, Lorenzo GD, Scarpati GD, Buonerba C. Anaplastic thyroid carcinoma: A comprehensive review of current and future therapeutic options. World J Clin Oncol. 2011; 2:150-157.

9. Smallridge RC, Marlow LA, Copland JA. Anaplastic thyroid cancer: molecular pathogenesis and emerging therapies. Endocr Relat Cancer. 2009; 16:17-44.

10. Carcangiu ML, Steeper T, Zampi G, Rosai J. Anaplastic thyroid carcinoma. A study of 70 cases. Am J Clin Pathol. 1985; 83:135-158.

11. Rivera M, Sang C, Gerhard R, Ghossein R, Lin O. Anaplastic thyroid carcinoma: morphologic findings and PAX-8 expression in cytology specimens. Acta Cytol. 2010; 54:668-672.

12. Salvatore G, Nappi TC, Salerno P, Jiang Y, Garbi C, Ugolini C, Miccoli P, Basolo F, Castellone MD, Cirafici AM, Melillo RM, Fusco A, Bittner ML, Santoro M. A cell proliferation and chromosomal instability signature in anaplastic thyroid carcinoma. Cancer Res. 2007; 67:1014810158.

13. Nikiforov YE. Genetic alterations involved in the transition from well-differentiated to poorly differentiated and anaplastic thyroid carcinomas. Endocr Pathol. 2004; 15:319-327.

14. Xing M. Genetic alterations in the phosphatidylinositol-3 kinase/Akt pathway in thyroid cancer. Thyroid. 2010; 20:697-706.

15. Knauf JA, MaX, Smith EP, Zhang L, Mitsutake N, Liao XH, Refetoff S, Nikiforov YE, Fagin JA. Targeted expression of BRAFV600E in thyroid cells of transgenic mice results in papillary thyroid cancers that undergo dedifferentiation. Cancer Res. 2005; 65:4238-4245.

16. Jhiang SM, Sagartz JE, Tong Q, Parker-Thornburg J, Capen CC, Cho JY, Xing S, Ledent C. Targeted expression of the ret/PTC1 oncogene induces papillary thyroid carcinomas. Endocrinology. 1996; 137:375-378.

17. Franco AT, Malaguarnera R, Refetoff S, Liao XH, Lundsmith E, Kimura S, Pritchard C, Marais R, Davies TF, Weinstein LS, Chen M, Rosen N, Ghossein R, Knauf JA, Fagin JA. Thyrotrophin receptor signaling dependence of Braf-induced thyroid tumor initiation in mice. Proc Natl Acad Sci U S A. 2011; 108:1615-1620.

18. Suzuki H, Willingham MC, Cheng SY. Mice with a mutation in the thyroid hormone receptor beta gene 
spontaneously develop thyroid carcinoma: a mouse model of thyroid carcinogenesis. Thyroid. 2002; 12:963-969.

19. Antico-Arciuch VG, Dima M, Liao XH, Refetoff S, Di Cristofano A. Cross-talk between PI3K and estrogen in the mouse thyroid predisposes to the development of follicular carcinomas with a higher incidence in females. Oncogene. 2010; 29:5678-5686.

20. Miller KA, Yeager N, Baker K, Liao XH, Refetoff S, Di Cristofano A. Oncogenic Kras requires simultaneous PI3K signaling to induce ERK activation and transform thyroid epithelial cells in vivo. Cancer Res. 2009; 69:3689-3694.

21. Knauf JA, Sartor MA, Medvedovic M, Lundsmith E, Ryder M, Salzano M, Nikiforov YE, Giordano TJ, Ghossein RA, Fagin JA. Progression of BRAF-induced thyroid cancer is associated with epithelial-mesenchymal transition requiring concomitant MAP kinase and TGFbeta signaling. Oncogene. 2011.

22. Yeager N, Klein-Szanto A, Kimura S, Di Cristofano A. Pten loss in the mouse thyroid causes goiter and follicular adenomas: insights into thyroid function and Cowden disease pathogenesis. Cancer Res. 2007; 67:959-966.

23. O'Reilly KE, Rojo F, She QB, Solit D, Mills GB, Smith D, Lane H, Hofmann F, Hicklin DJ, Ludwig DL, Baselga J, Rosen N. mTOR inhibition induces upstream receptor tyrosine kinase signaling and activates Akt. Cancer Res. 2006; 66:1500-1508.

24. Giordano TJ, Au AY, Kuick R, Thomas DG, Rhodes DR, Wilhelm KG, Jr., Vinco M, Misek DE, Sanders D, Zhu Z, Ciampi R, Hanash S, Chinnaiyan A, Clifton-Bligh RJ, Robinson BG, Nikiforov YE et al. Delineation, functional validation, and bioinformatic evaluation of gene expression in thyroid follicular carcinomas with the PAX8-PPARG translocation. Clin Cancer Res. 2006; 12:1983-1993.

25. Borup R, Rossing M, Henao R, Yamamoto Y, Krogdahl A, Godballe C, Winther O, Kiss K, Christensen L, Hogdall E, Bennedbaek F, Nielsen FC. Molecular signatures of thyroid follicular neoplasia. Endocr Relat Cancer. 2010; 17:691708.

26. Liberzon A, Subramanian A, Pinchback R, Thorvaldsdottir H, Tamayo P, Mesirov JP. Molecular signatures database (MSigDB) 3.0. Bioinformatics. 2011; 27:1739-1740.

27. Rodrigues RF, Roque L, Krug T, Leite V. Poorly differentiated and anaplastic thyroid carcinomas: chromosomal and oligo-array profile of five new cell lines. British journal of cancer. 2007; 96:1237-1245.

28. Griffith OL, Melck A, Jones SJ, Wiseman SM. Metaanalysis and meta-review of thyroid cancer gene expression profiling studies identifies important diagnostic biomarkers. J Clin Oncol. 2006; 24:5043-5051.

29. Azumi M, Kobayashi H, Aoki N, Sato K, Kimura S, Kakizaki H, Tateno M. Six-transmembrane epithelial antigen of the prostate as an immunotherapeutic target for renal cell and bladder cancer. J Urol. 2010; 183:2036-2044.

30. Kim S, Kang HY, Nam EH, Choi MS, Zhao XF, Hong CS, Lee JW, Lee JH, Park YK. TMPRSS4 induces invasion and epithelial-mesenchymal transition through upregulation of integrin alpha5 and its signaling pathways. Carcinogenesis. 2010; 31:597-606.

31. Toure A, Mzali R, Liot C, Seguin L, Morin L, Crouin C, Chen-Yang I, Tsay YG, Dorseuil O, Gacon G, Bertoglio J. Phosphoregulation of MgcRacGAP in mitosis involves Aurora B and Cdk1 protein kinases and the PP2A phosphatase. FEBS Lett. 2008; 582:1182-1188.

32. Roostalu J, Schiebel E, Khmelinskii A. Cell cycle control of spindle elongation. Cell Cycle. 2010; 9:1084-1090.

33. Asteriti IA, Rensen WM, Lindon C, Lavia P, Guarguaglini G. The Aurora-A/TPX2 complex: a novel oncogenic holoenzyme? Biochim Biophys Acta. 2010; 1806:230-239.

34. Scarpulla RC. Metabolic control of mitochondrial biogenesis through the PGC-1 family regulatory network. Biochim Biophys Acta. 2011; 1813:1269-1278.

35. Warburg O, Wind F, Negelein E. The Metabolism of Tumors in the Body. J Gen Physiol. 1927; 8:519-530.

36. Poisson $\mathrm{T}$, Deandreis $\mathrm{D}$, Leboulleux $\mathrm{S}$, Bidault $\mathrm{F}$, Bonniaud G, Baillot S, Auperin A, Al Ghuzlan A, Travagli JP, Lumbroso J, Baudin E, Schlumberger M. $18 \mathrm{~F}$-fluorodeoxyglucose positron emission tomography and computed tomography in anaplastic thyroid cancer. Eur J Nucl Med Mol Imaging. 2010; 37:2277-2285.

37. Dwarakanath B, Jain V. Targeting glucose metabolism with 2-deoxy-D-glucose for improving cancer therapy. Future Oncol. 2009; 5:581-585.

38. Maschek G, Savaraj N, Priebe W, Braunschweiger P, Hamilton K, Tidmarsh GF, De Young LR, Lampidis TJ. 2-deoxy-D-glucose increases the efficacy of adriamycin and paclitaxel in human osteosarcoma and non-small cell lung cancers in vivo. Cancer Res. 2004; 64:31-34.

39. Simons AL, Ahmad IM, Mattson DM, Dornfeld KJ, Spitz DR. 2-Deoxy-D-glucose combined with cisplatin enhances cytotoxicity via metabolic oxidative stress in human head and neck cancer cells. Cancer research. 2007; 67:33643370 .

40. Chou TC, Talalay P. Quantitative analysis of dose-effect relationships: the combined effects of multiple drugs or enzyme inhibitors. Adv Enzyme Regul. 1984; 22:27-55.

41. Ricarte-Filho JC, Ryder M, Chitale DA, Rivera M, Heguy A, Ladanyi M, Janakiraman M, Solit D, Knauf JA, Tuttle RM, Ghossein RA, Fagin JA. Mutational profile of advanced primary and metastatic radioactive iodinerefractory thyroid cancers reveals distinct pathogenetic roles for BRAF, PIK3CA, and AKT1. Cancer Res. 2009; 69:4885-4893.

42. Fagin JA, Matsuo K, Karmakar A, Chen DL, Tang SH, Koeffler HP. High prevalence of mutations of the p53 gene 
in poorly differentiated human thyroid carcinomas. J Clin Invest. 1993; 91:179-184.

43. Ganapathy-Kanniappan S, Vali M, Kunjithapatham R, Buijs M, Syed LH, Rao PP, Ota S, Kwak BK, Loffroy R, Geschwind JF. 3-bromopyruvate: a new targeted antiglycolytic agent and a promise for cancer therapy. Current pharmaceutical biotechnology. 2010; 11:510-517.

44. Ko YH, Smith BL, Wang Y, Pomper MG, Rini DA, Torbenson MS, Hullihen J, Pedersen PL. Advanced cancers: eradication in all cases using 3-bromopyruvate therapy to deplete ATP. Biochem Biophys Res Commun. 2004; 324:269-275.

45. Chen AY, Jemal A, Ward EM. Increasing incidence of differentiated thyroid cancer in the United States, 19882005. Cancer. 2009; 115:3801-3807.

46. Siegel R, Ward E, Brawley O, Jemal A. Cancer statistics, 2011. CA: A Cancer Journal for Clinicians. 2011; 61:212236.

47. Liu Z, Hou P, Ji M, Guan H, Studeman K, Jensen K, Vasko V, El-Naggar AK, Xing M. Highly prevalent genetic alterations in receptor tyrosine kinases and phosphatidylinositol 3-kinase/akt and mitogen-activated protein kinase pathways in anaplastic and follicular thyroid cancers. J Clin Endocrinol Metab. 2008; 93:3106-3116.

48. Gauchotte G, Philippe C, Lacomme S, Leotard B, Wissler MP, Allou L, Toussaint B, Klein M, Vignaud JM, Bressenot A. BRAF, p53 and SOX2 in anaplastic thyroid carcinoma: evidence for multistep carcinogenesis. Pathology. 2011; 43:447-452.

49. Liu J, Brown RE. Immunohistochemical detection of epithelialmesenchymal transition associated with stemness phenotype in anaplastic thyroid carcinoma. Int J Clin Exp Pathol. 2010; 3:755-762.

50. Scheel C, Eaton EN, Li SH, Chaffer CL, Reinhardt F, Kah KJ, Bell G, Guo W, Rubin J, Richardson AL, Weinberg RA. Paracrine and autocrine signals induce and maintain mesenchymal and stem cell states in the breast. Cell. 2011; 145:926-940.

51. Perona R, Lopez-Ayllon BD, de Castro Carpeno J, BeldaIniesta C. A role for cancer stem cells in drug resistance and metastasis in non-small-cell lung cancer. Clinical \& translational oncology : official publication of the Federation of Spanish Oncology Societies and of the National Cancer Institute of Mexico. 2011; 13:289-293.

52. Chakravarty D, Santos E, Ryder M, Knauf JA, Liao XH, West BL, Bollag G, Kolesnick R, Thin TH, Rosen N, Zanzonico P, Larson SM, Refetoff S, Ghossein R, Fagin JA. Small-molecule MAPK inhibitors restore radioiodine incorporation in mouse thyroid cancers with conditional BRAF activation. J Clin Invest. 2011.

53. Lu C, Zhao L, Ying H, Willingham MC, Cheng SY. Growth activation alone is not sufficient to cause metastatic thyroid cancer in a mouse model of follicular thyroid carcinoma. Endocrinology. 2010; 151:1929-1939.

54. Perroud B, Lee J, Valkova N, Dhirapong A, Lin PY, Fiehn O, Kultz D, Weiss RH. Pathway analysis of kidney cancer using proteomics and metabolic profiling. Molecular cancer. 2006; 5:64.

55. Manfredi MG, Ecsedy JA, Chakravarty A, Silverman L, Zhang M, Hoar KM, Stroud SG, Chen W, Shinde V, Huck JJ, Wysong D, Janowick D, Hyer M, Leroy PJ, Gershman R, Silva M et al. Characterization of Alisertib (MLN8237), An Investigational Small Molecule Inhibitor of Aurora A Kinase Using Novel In Vivo Pharmacodynamic Assays. Clin Cancer Res. 2011.

56. Steegmaier M, Hoffmann M, Baum A, Lenart P, Petronczki M, Krssak M, Gurtler U, Garin-Chesa P, Lieb S, Quant J, Grauert M, Adolf GR, Kraut N, Peters JM, Rettig WJ. BI 2536, a potent and selective inhibitor of polo-like kinase 1, inhibits tumor growth in vivo. Curr Biol. 2007; 17:316-322.

57. Nappi TC, Salerno P, Zitzelsberger H, Carlomagno F, Salvatore G, Santoro M. Identification of Polo-like kinase 1 as a potential therapeutic target in anaplastic thyroid carcinoma. Cancer Res. 2009; 69:1916-1923.

58. Zhou Y, Tozzi F, Chen J, Fan F, Xia L, Wang J, Gao G, Zhang A, Xia X, Brasher H, Widger W, Ellis LM, Weihua Z. Intracellular ATP levels are a pivotal determinant of chemoresistance in colon cancer cells. Cancer Res. 2011.

59. Mohanti BK, Rath GK, Anantha N, Kannan V, Das BS, Chandramouli BA, Banerjee AK, Das S, Jena A, Ravichandran R, Sahi UP, Kumar R, Kapoor N, Kalia VK, Dwarakanath BS, Jain V. Improving cancer radiotherapy with 2-deoxy-D-glucose: phase I/II clinical trials on human cerebral gliomas. International journal of radiation oncology, biology, physics. 1996; 35:103-111.

60. Vander Heiden MG. Targeting cancer metabolism: a therapeutic window opens. Nature reviews Drug discovery. 2011; 10:671-684.

61. Pohlenz J, Maqueem A, Cua K, Weiss RE, Van Sande J, Refetoff S. Improved radioimmunoassay for measurement of mouse thyrotropin in serum: strain differences in thyrotropin concentration and thyrotroph sensitivity to thyroid hormone. Thyroid. 1999; 9:1265-1271.

62. Dima M, Miller KA, Antico-Arciuch VG, Di Cristofano A. Establishment and characterization of cell lines from a novel mouse model of poorly differentiated thyroid carcinoma: powerful tools for basic and preclinical research. Thyroid. 2011;21:1001-1007. 